\title{
Implementing the Janani Suraksha Yojana: Perspectives and experiences of Accredited Social Health Activists in Rajasthan
}

\author{
K.G. Santhya \\ Population Council \\ Shireen J. Jejeebhoy \\ Population Council \\ A.J. Francis Zavier \\ Population Council
}

Follow this and additional works at: https://knowledgecommons.popcouncil.org/departments_sbsr-pgy

Part of the International Public Health Commons, Maternal and Child Health Commons, Social and Behavioral Sciences Commons, and the Women's Health Commons How does access to this work benefit you? Let us know!

\section{Recommended Citation}

Santhya, K.G., Shireen J. Jejeebhoy, and A.J. Francis Zavier. 2011. "Implementing the Janani Suraksha Yojana: Perspectives and experiences of Accredited Social Health Activists in Rajasthan." New Delhi: Population Council. 

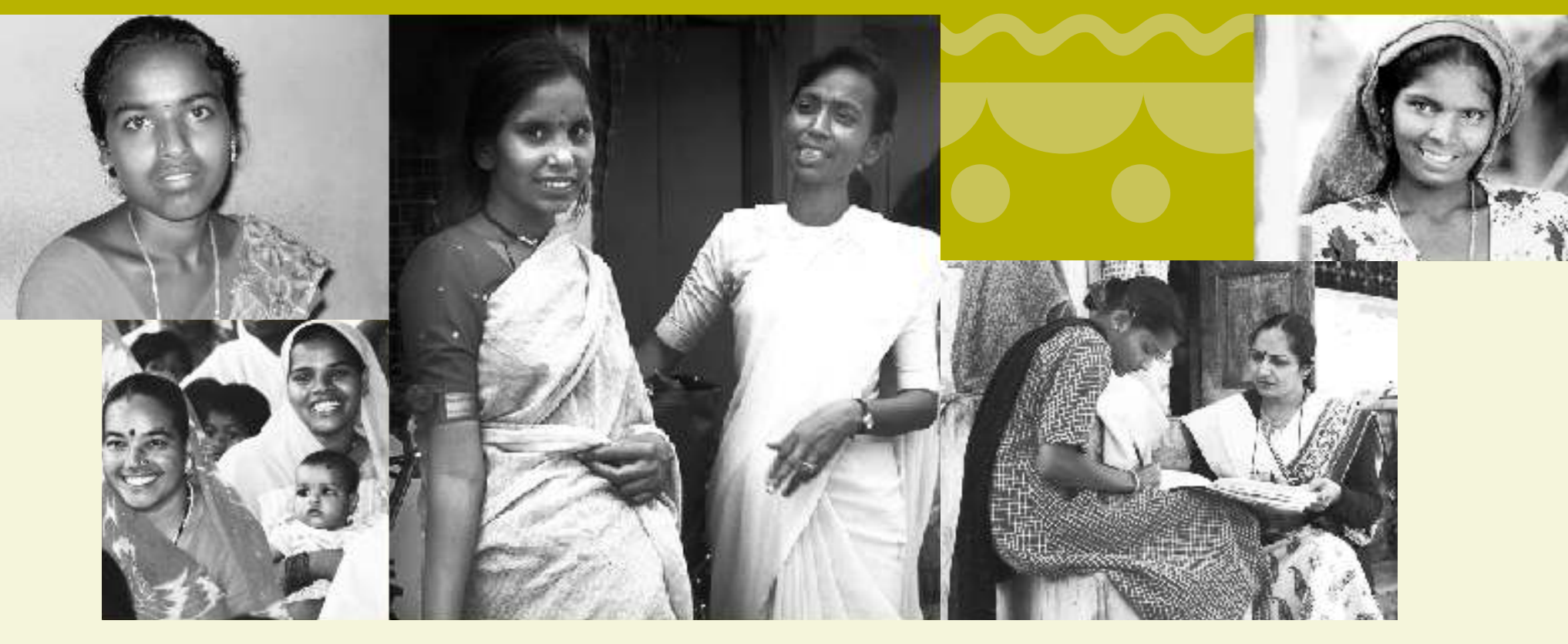

\section{Implementing the Janani Suraksha Yojana: Perspectives and experiences of Accredited Social Health Activists in Rajasthan}


This report is the result of an exploratory study of ASHAs, conducted as part of a large-scale evaluation of the Janani Suraksha Yojana in rural and urban settings of the north-western state of Rajasthan, India. The study assessed the perceptions and experiences of ASHAs with regard to the implementation of the JSY.

For additional copies of this report, please contact:

Population Council

Zone 5-A, Ground Floor

India Habitat Centre

Lodi Road

New Delhi -110003

Phone: 011-2464 2901/02

Email: info-india@popcouncil.org

Web site: http://www.popcouncil.org/asia/india/html

The Population Council is an international, non-profit, non-governmental organisation that seeks to improve the well-being and reproductive health of current and future generations around the world and to help achieve a humane, equitable and sustainable balance between people and resources. The Council conducts biomedical, social science and public health research, and helps build research capacities in developing countries.

Copyright $\odot 2011$ Population Council

Suggested citation: Santhya, K. G., S.J. Jejeebhoy and A.J. Francis Zavier. 2011. Implementing the Janani Suraksha Yojana: Perspectives and experiences of Accredited Social Health Activists in Rajasthan. New Delhi: Population Council. 

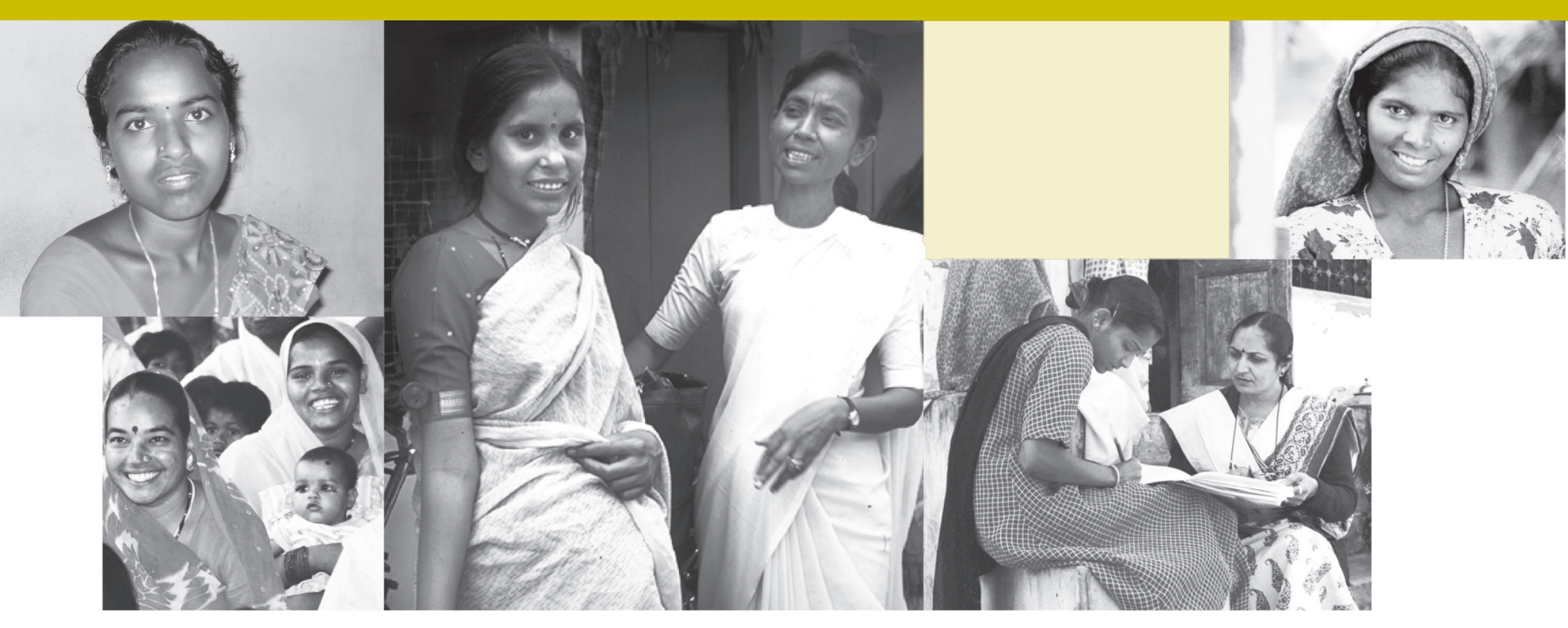

\title{
Implementing the Janani Suraksha Yojana: Perspectives and experiences of Accredited Social Health Activists in Rajasthan
}

\author{
K.G. Santhya
}

Shireen J. Jejeebhoy

A.J. Francis Zavier 


\section{柆} -

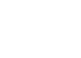
. .
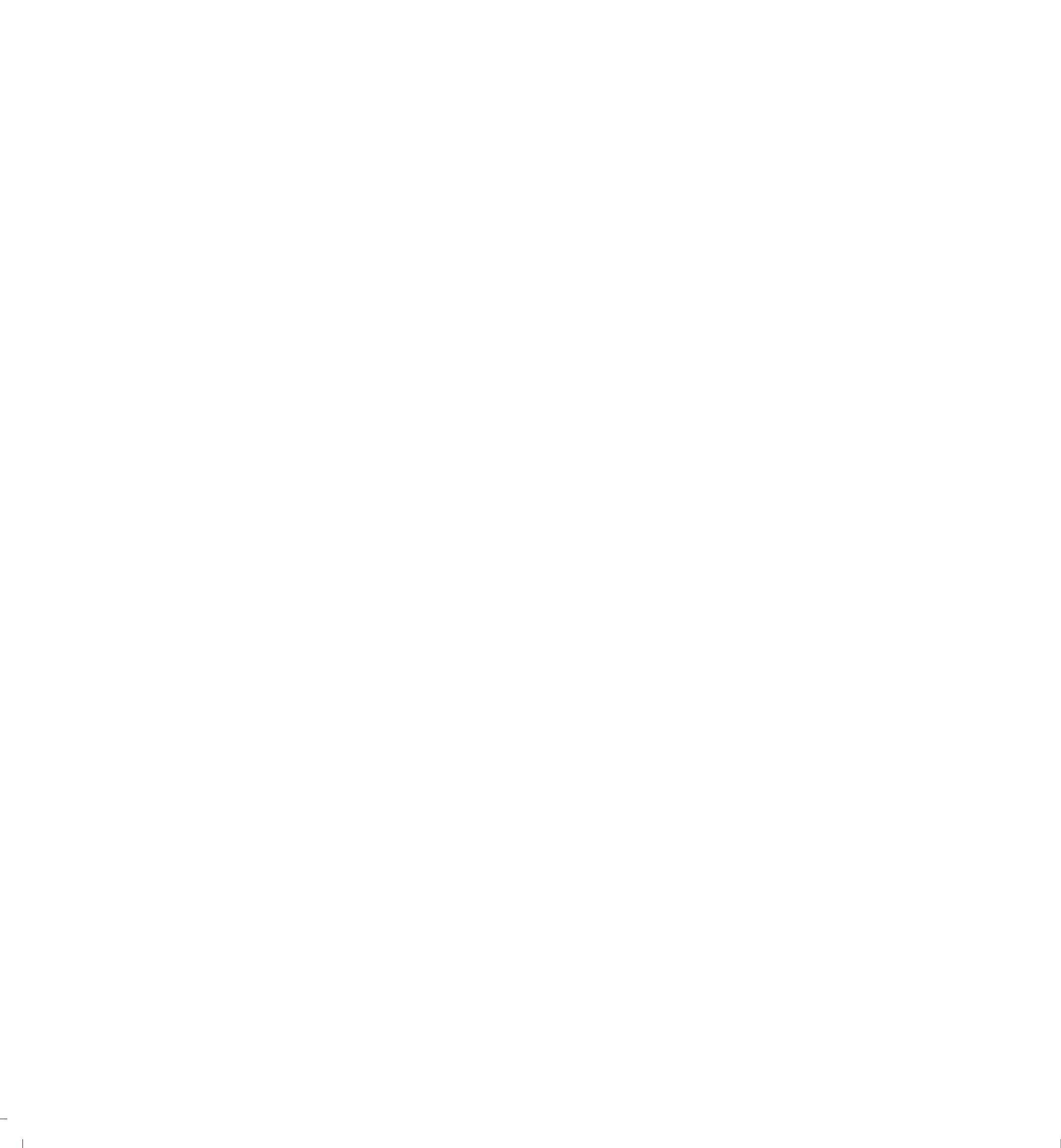

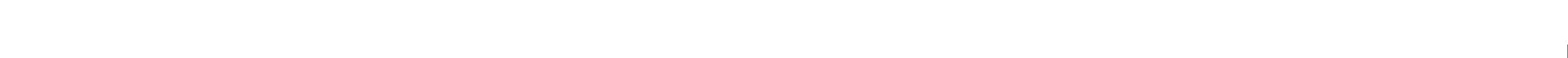

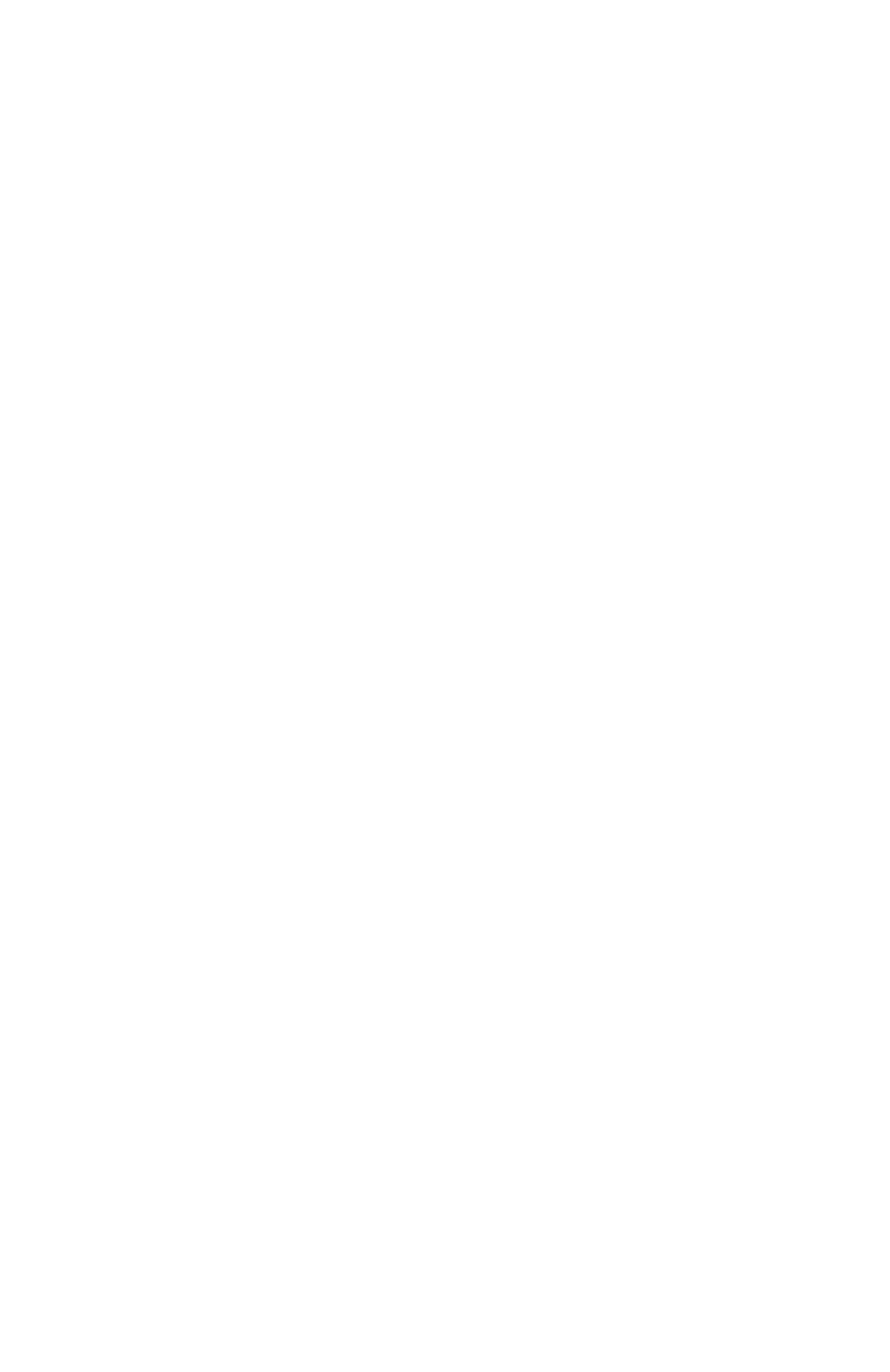




\section{Contents}

Acknowledgements

Executive summary

viii

Recommendations

Chapter 1: Introduction

Background

Study objectives

Study setting

Study design

Characteristics of respondents

Structure of the report

Chapter 2: Awareness of the JSY among ASHAs 7

Awareness of eligibility conditions for availing of the JSY 7

Awareness of entitlements of beneficiaries and ASHAs under the JSY 8

Awareness of the ASHA's responsibilities under the JSY 9

Awareness of schemes other than the JSY 10

Chapter 3: Extent of training and supportive supervision received by ASHAs 12

Training received by ASHAs in imparting information on sexual and reproductive matters 12

Supportive supervision received by ASHAs 13

Confidence at work among ASHAs and their perceived credibility 14

Chapter 4: Awareness of maternal and newborn care practices among ASHAs 15

Awareness of antenatal care practices 15

Awareness of birth preparedness matters 16

Awareness of postpartum care practices 16

Awareness of newborn care practices 17

Awareness of maternal and newborn complications 19

Knowledge of contraceptive methods 22 
Chapter 5: Services provided by ASHAs

Antenatal care services

Delivery care services

Postpartum and newborn care services

Contraceptive counseling and supplies

Services given to women to access the JSY cash benefit

Incentives received by ASHAs

Difficulties experienced by ASHAs in carrying out JSY-related tasks

Perceptions of ASHAs about the JSY

Chapter 6: Summary and recommendations

Recommendations

Appendix 1: Janani Suraksha Yojana (JSY): Features and Frequently Asked Questions and Answers 34

References

Members of the study team 


\section{List of tables}

Table 1.1 Profile of the study districts and Rajasthan state 4

Table $1.2 \quad$ Coverage of the study 5

Table 1.3 Socio-demographic characteristics of respondents 6

Table 2.1 Percentage of ASHAs reporting correct awareness of eligibility conditions for availing of the JSY, according to residence 8

Table 2.2 Percentage of ASHAs reporting awareness of their responsibilities $\begin{array}{ll}\text { under the JSY, according to residence } & 10\end{array}$

Table 3.1 Percentage of ASHAs who had received training in imparting information on $\begin{array}{ll}\text { sexual and reproductive matters, according to residence } & 12\end{array}$

Table 3.2 Percentage of ASHAs reporting availability and use of IEC materials on sexual and reproductive topics

Table 4.1 Percentage of ASHAs reporting awareness of newborn care practices, according to residence

Table 4.2 Percentage of ASHAs reporting correct awareness of maternal and newborn complications, according to residence

Table 4.3 ASHAs' awareness of recommended facilities to which a pregnant woman who experiences selected pregnancy-related complications must go for treatment

Table 5.1 Percentage of ASHAs by antenatal care services provided to pregnant women in the three months preceding the interview, according to residence

Table 5.2 Percentage of ASHAs by delivery care services provided to pregnant women in the three months preceding the interview, according to residence

Table 5.3 Percentage of ASHAs by reasons cited for recommending a particular health facility, according to type of health facility

Table 5.4 Percentage of ASHAs by postpartum and newborn care services provided to recently-delivered women in the three months preceding the interview, according to residence

Table 5.5 Percentage of ASHAs reporting experiences of assisting women to obtain the JSY cash benefit in the three months preceding the interview, according to residence 28

Table 5.6 Percentage of ASHAs who received the JSY cash incentive, according to residence

Table 5.7 Percentage of ASHAs by difficulties experienced in carrying out JSY-related tasks, according to residence

Table 5.8 Percentage of ASHAs reporting perceptions about the JSY, according to residence

Table 5.9 Percentage of ASHAs by suggestions offered for improving JSY implementation, according to residence 


\section{List of figures}

Figure 2.1 Awareness of ASHAs about women's monetary and non-monetary entitlements under the JSY, according to residence

Figure 2.2 Awareness of ASHAs about their own entitlements under the JSY, according to residence

Figure 2.3 Awareness of schemes other than the JSY among ASHAs, according to residence

Figure 3.1 Percentage of ASHAs reporting having received supportive supervision from ANMs, according to residence

Figure 3.2 Confidence at work among ASHAs and their perceived credibility, according to residence

Figure 4.1 Awareness of antenatal care practices among ASHAs, according to residence

Figure 4.2

Awareness of birth preparedness among ASHAs, according to residence

Figure 4.3 Awareness of postpartum care practices among ASHAs, according to residence

Figure 4.4 Awareness of three or more maternal and newborn complications among ASHAs, according to residence

Figure 4.5 Correct specific knowledge of contraceptive methods among ASHAs, according to residence

Figure 5.1 Contraceptive counseling and supplies provided by ASHAs to women and men in the three months preceding the interview, according to residence 


\section{Acknowledgements}

This study has benefited immeasurably from the input of many. We are extremely grateful to the John D. and Catherine T. MacArthur Foundation for their support, which made this study possible.

The Department of Health and Family Welfare, Rajasthan granted permission to conduct the study and offered their unstinting support at all stages of the project and we take this opportunity to express our gratitude for their support and guidance to Meghraj Meena, Former District Reproductive and Child Health

Officer, Alwar; Nanda Charan, Reproductive and Child Health Officer, Jodhpur; Subodh Agarwal and Ramesh Mathur, Former Chief Medical and Health Officers, Alwar and Jodhpur districts respectively; and Mohit Sharma, Former District Programme Manager, Jodhpur. Our thanks also go to the grass-root level workers of the department who generously supported the field team in data collection. The State Census Office in Rajasthan provided the project with census enumeration block maps and their support is gratefully acknowledged.

The Technical Advisory Group—Dinesh Agarwal, Kiran Ambwani, Dipa Nag Chowdhury, Aparajita Gogoi, Poonam Muttreja, Saroj Pachauri, Amit Mohan Prasad and Rajni Ved—provided invaluable advice in developing the study instruments, project design, and interpreting the findings.

We acknowledge with gratitude the contribution of Aparajita Gogoi and Rajni Ved for reviewing an earlier draft of this report and providing insightful comments and suggestions. We would like to gratefully acknowledge support received from Rajib Acharya for developing the study instruments and the data entry package that enabled interviewers to conduct interviews and record responses directly onto mini laptops, Shveta Kalyanwala for developing the study instruments and training the field team, (Late) Rajesh Kumar for translating the instruments and Jyoti Moodbidri for her editorial contribution. The contributions of Komal Saxena in preparing the report and ably coordinating the printing of the report, Shilpi Rampal for testing the data entry package, M.A. Jose for ably managing the administrative aspects of this project, and B. Srihari for the overall management of the field work are much appreciated.

Finally, and most importantly, we would like to thank the ASHAs of Alwar and Jodhpur districts, Rajasthan who generously gave us their time and shared their views and experiences, and the investigators and other members of the field team who painstakingly collected the qualitative and survey data. 


\section{Executive summary}

A major initiative launched under the National Rural Health Mission (NRHM) to address demand-side barriers to improving maternal and newborn health, in particular, and reproductive health, more generally, in India, is the introduction of the Accredited Social Health Activist (ASHA). A number of evaluations of the ASHA programme have been undertaken to date, and the programme has, by and large, been positively assessed, although a number of issues remain with regard to the ASHA's training, performance, incentive payment and supervision. To extend the evidence base on the perspectives and experiences of ASHAs in the implementation of the Janani Suraksha Yojana (JSY), the Population Council undertook a study of ASHAs in two districts of the north-western state of Rajasthan, India.

The study was conducted as part of a large-scale evaluation of the JSY that comprised a survey of nearly 5,000 women aged below 35 years who had delivered in the one year preceding the interview and in-depth interviews with selected survey respondents, conducted between September 2009 and February 2010. ASHAs available in the villages and urban wards selected for the survey of women were invited to participate in the study. ASHAs were serving in 79 of the 96 villages and 54 of the 100 urban wards included in the study. A total of 172 ASHAs were listed; of these, 150 were successfully interviewed.

\section{Awareness of the JSY among ASHAs varies by theme and is far from comprehensive}

Awareness of the JSY programme among ASHAs varied by theme and was far from comprehensive. The vast majority of ASHAs were aware of most of the eligibility conditions for availing of JSY benefits, including the fact that women could access JSY benefits regardless of their age, parity and household economic status, as well as the type of government health facility in which they could deliver to acquire these benefits. However, their awareness of the monetary and non-monetary support to which women are entitled under the JSY was somewhat limited. For example, only 71 percent of ASHAs knew that a woman in rural areas is entitled to Rs. 1,400 and that a woman in urban areas is entitled to Rs. 1,000 if she delivers in a government or accredited private facility. Findings, moreover, indicate considerable confusion among ASHAs with regard to their awareness of their own entitlements for assisting women to access JSY benefits. Likewise, findings present a mixed picture about their awareness of their responsibilities under the JSY. Tasks such as assisting pregnant women in registering for antenatal check-ups and seeking three antenatal check-ups, counseling them about institutional delivery, assisting them in identifying a health facility for delivery, escorting them to a health facility for delivery, making postpartum visits to them within seven days of delivery and arranging immunisation of their newborn were almost universally known. In contrast, such tasks as counseling recentlydelivered women about family planning were rarely known to be among the responsibilities of the ASHA. 


\section{While most ASHAs have been trained in imparting information on sexual and reproductive matters, supportive supervision remains limited}

Almost all ASHAs had received training in imparting information pertaining to contraception, care during pregnancy, delivery and the postpartum period, and newborn care. However, the extent of supervision that they received was far from satisfactory. For example, just two-fifths of ASHAs reported that the auxiliary-nurse-midwife (ANM) had held weekly or fortnightly meetings with them in the one month preceding the survey.

\section{The credibility of ASHAs with women and their family remains low}

Findings show that while most ASHAs were confident about performing the tasks assigned to them, many believed that their credibility among women in their community was limited. Only one-quarter of ASHAs felt that women in their community took their advice seriously.

\section{Awareness of maternal and newborn care practices among ASHAs is mixed}

ASHAs displayed in-depth awareness of best maternal and newborn care practices. For example, awareness of the number of antenatal check-ups, the required number of doses of tetanus toxoid (TT) injections and the number of days that iron and folic acid (IFA) supplementation should be taken was almost universal. However, awareness of the appropriate timing of the first, second and third antenatal check-ups was somewhat limited. With regard to delivery care, the majority of ASHAs were aware of some of the essential birth preparations. Nine out of ten ASHAs knew that a woman should have a postpartum check-up even if she is feeling fine; however, fewer knew that a woman should have her first postpartum check-up within a few hours or, at best, within two days of delivery.

Findings show that the vast majority of ASHAs were aware of the best practices related to immediate care of the newborn. Awareness of appropriate infant feeding practices, likewise, was high. Similarly, awareness of the immunisation schedule was high.

The majority of ASHAs were aware of the complications that can occur during the antenatal period as well as those among newborns. However, fewer were aware of complications during labour and delivery and the postpartum period. Findings, moreover, indicate limited awareness of appropriate health facilities for treating pregnancy-related complications. For example, just one-third of ASHAs knew that a pregnant woman who experiences antepartum bleeding must go to a community health centre which is the recommended lowest level facility.

Finally, in-depth awareness of contraceptive methods was high among ASHAs; for example, over 90 percent of ASHAs knew that a woman should take oral contraceptives daily or weekly and that one condom can be used for just one sexual act. 


\section{Services provided by the ASHAs remain skewed}

Almost all ASHAs had counseled pregnant women about antenatal care; assisted pregnant women in registering for antenatal services, accessing nutritious food from Anganwadi centres and identifying a health facility for delivery, visited recently-delivered women within a week of delivery, and assisted women in getting their baby immunised. However, fewer had assisted pregnant women in receiving three antenatal checkups, escorted them to a health facility for delivery, arranged transport for them to reach a health facility for delivery and stayed with them till they were discharged after delivery.

Findings also indicate that the interactions of ASHAs with married young women appear to be limited; just one-third of ASHAs reported giving information on family planning to newly-married women in the three months preceding the interview.

The information imparted by ASHAs to women in the community was also skewed. ASHAs who had counseled pregnant women about care during pregnancy had typically discussed the importance of three antenatal check-ups, TT injections and IFA supplements. Such topics as delivery preparations and danger signs experienced during the antenatal period, delivery and the postpartum period, as well as those among newborns had been discussed by fewer ASHAs. Likewise, ASHAs who had made postpartum visits, had typically discussed how to take care of the newborn and the mother, and breastfeeding, while such topics as the importance of postpartum check-ups, danger signs during the postpartum period, danger signs among newborns and postpartum contraception had rarely been discussed.

\section{On average, ASHAs assist one woman to avail of JSY benefits in a month}

Over 90 percent of ASHAs reported that they had assisted pregnant and recently-delivered women to obtain JSY benefits, with little rural-urban difference. On average, they had assisted one woman in a month.

\section{Most ASHAs received incentives for assisting women to access JSY benefits; however, sizeable numbers experienced delays in payment}

Almost nine out of 10 ASHAs had received some money from the health department for assisting women to access JSY benefits. For the last woman whom they had assisted, ASHAs in rural and urban areas had received on average Rs. 424 and Rs. 138, respectively. One in five ASHAs had experienced some difficulty in obtaining the money, primarily related to delays in receiving payments.

\section{Recommendations}

The findings of the study suggest a number of priority areas for action.

\section{Train ASHAs more comprehensively about their rights and responsibilities under the NRHM}

Findings highlight that several of the tasks articulated under the JSY are not recognised by ASHAs to be among their responsibilities. For example, staying with women till they are discharged from the health facility 
after delivery and counseling women about breastfeeding and postpartum contraception were not widely known as the responsibilities of the ASHA. Moreover, there exists considerable confusion about the ASHA's entitlements. These findings emphasise the need for efforts to better inform ASHAs about their entitlements and responsibilities under the NRHM.

\section{Raise awareness of the lesser known best practices related to maternal and newborn care among} ASHAs

ASHAs in our study displayed high levels of awareness of best practices related to maternal and newborn care; however, findings that their awareness of the appropriate timing of antenatal and postpartum checkups is rather limited, call for further efforts to raise their awareness of maternal and newborn care practices. These efforts must pay special attention to increasing their awareness of the complications that a woman may experience during labour and delivery, and the postpartum period and the appropriate health facilities for treating pregnancy-related complications.

\section{Emphasise the ASHA's engagement in promoting postpartum care}

Findings that the ASHA's engagement is largely limited to promoting antenatal and delivery care highlight the need to emphasise her role in promoting postpartum care, given that most maternal deaths take place during the postpartum period.

\section{Make special efforts to increase the credibility of ASHAs in the community}

Findings that most ASHAs perceive that women in their community rarely take their advice seriously call for efforts to increase their social skills, including interpersonal communication and self-esteem on the one hand and to promote ASHAs as frontline health workers in the community, on the other. Mechanisms to provide supportive supervision to ASHAs by ANMs and medical officers need to be strengthened. At the same time, ANMs and medical officers must, in their contacts with women and their family members, communicate the important role played by ASHAs vis-à-vis the health of their community, and convey the health system's confidence in their abilities. 

(1) 


\section{CHAPTER 1}

\section{Introduction}

A major initiative launched under the National Rural Health Mission (NRHM) to address demandside barriers to improving maternal and newborn health, in particular, and reproductive health, more generally, in India, is the introduction of the Accredited Social Health Activist (ASHA). Drawn from the community and accountable to it, the ASHA is trained to act as the interface between the public health system and the community. Under the Janani Suraksha Yojana (JSY), the ASHA is entrusted with a number of responsibilities aimed at enabling women to access maternal and child health services and related benefits offered by the scheme (Ministry of Health and Family Welfare, 2006). Currently, there are 8.3 lakh ASHAs across the country (Ministry of Health and Family Welfare, 2011a). Evaluations of the ASHA programme conducted to date (Centre for Operations Research and Training, 2007a; 2007b; 2007c; 2007d; 2007e; 2007f; 2008a; 2008b; Ministry of Health and Family Welfare, 2011b; 2011c; United Nations Population Fund, 2009) have, by and large, positively assessed the programme, although a number of issues remain with regard to their training, performance, incentive payment and supervision.

Drawing on data from 150 ASHAs interviewed as part of a large-scale evaluation of the JSY in two districts of Rajasthan, this report extends the evidence base on the perspectives and experiences of ASHAs in the implementation of the JSY. Findings pertaining to the perspectives of women and such health care providers as medical officers and auxiliary-nurse-midwives (ANMs) from the larger study are presented in separate reports.

\section{Background}

The Janani Suraksha Yojana entrusts ASHAs with a number of responsibilities so as to enable women to avail of maternal and child health services and related JSY benefits (Ministry of Health and Family Welfare, 2006). These responsibilities include (a) identifying pregnant women and facilitating their registration for antenatal care (ANC); (b) ensuring that pregnant women receive at least three antenatal checkups including tetanus toxoid (TT) injections and iron and folic acid (IFA) tablets; (c) identifying a functional government health facility or an accredited private health facility for referral and delivery; (d) counseling pregnant women to undergo an institutional delivery; (e) arranging transport for pregnant women to reach the health centre for delivery or treatment of complications; (f) escorting pregnant women to a pre-determined health facility and staying with them till they are discharged; (g) counseling women about breastfeeding the newborn within one hour of delivery and its continuation till the infant is 3-6 months of age; (h) arranging immunisation of the newborn up to the age of 14 weeks; (i) making a postpartum visit within seven days of delivery to track the mother's health after delivery and facilitate obtaining care; and (j) promoting family planning services (See Appendix 1 for a copy of the document from the Ministry of Health and Family Welfare detailing the responsibilities of ASHAs under the JSY). ASHAs who assist pregnant women in accessing maternal and child health services are provided an incentive amount of Rs. 600 and Rs. 200 in rural and urban areas, respectively. 
A recent evaluation of ASHAs conducted by the National Health Systems Resource Centre in eight states observes that the programme has been successful in generating demand for public health services as measured by the increase in institutional delivery rates and immunisation coverage (Ministry of Health and Family Welfare, 2011b). It further observes that considerable progress has been made by ASHAs in taking on the role of frontline community health workers in settings where support systems are in place. The Common Review Mission of the NRHM, likewise, observes that "there is no other component/parameter of NRHM progress which so uniformly receives positive reports as the ASHA programme" (Ministry of Health and Family Welfare, 2011c).

At the same time, several concerns remain with regard to the training, performance, incentive payment and supervision of ASHAs. For example, just 44 percent of ASHAs have undergone the required training comprising five modules (Ministry of Health and Family Welfare, 2011a). Moreover, the mid-term appraisal of the Eleventh Five Year Plan underscores that ASHAs are inadequately trained (Planning Commission, 2011). Concerns have also been raised about their performance being focused disproportionately on certain tasks. For example, the mid-term appraisal of the Eleventh Five Year Plan observes that the ASHA's only focus is on facilitating institutional deliveries. The eight-state evaluation of ASHAs, likewise, observes that ASHAs have not been as effective in promoting such practices as ensuring three or more antenatal check-ups, postpartum care, breastfeeding, complementary feeding and family planning as promoting institutional deliveries and immunisation of infants (Ministry of Health and Family Welfare, 2011b). The evaluation further notes that although 90 percent of ASHAs were engaged in promoting institutional delivery, they had not met over 20 percent of pregnant women even in the best-performing districts and that this percentage was as high as 50 in poor-performing districts where the ASHA's support is needed most. Similarly, an evaluation of ASHAs in five states reports that while most ASHAs mentioned that they assisted pregnant women to access antenatal services, accompanied them to a hospital for delivery and assisted recently-delivered women in getting their newborn immunised, fewer advised recently-delivered women about postpartum care and feeding practices (UNFPA, 2009). The evaluation, moreover, observes that the ASHAs contacted fewer than the actual number of pregnant and recently-delivered women in their catchment areas.

Evaluations have also observed that ASHAs have not been equipped with the knowledge and skills to act as frontline health workers. For example, an evaluation, conducted in 2007, of 150-180 ASHAs in seven states who had undergone ASHA training and had been working as ASHAs for at least six months prior to the interview, reports that their awareness of maternal and newborn danger signals was not comprehensive in any setting, and that awareness levels varied by state and the topic under consideration (Centre for Operations Research and Training, 2007a; 2007b; 2007c; 2007d; 2007e; 2007f; 2008a; 2008b). For example, between 50 percent and 80 percent of ASHAs in the seven states could identify excessive bleeding as a danger signal, and many fewer-between one-fifth and one-quarter-could identify foetal distress as a danger signal. With regard to newborn risk, only between one-third and two-thirds of ASHAs were aware that the newborn is most at risk immediately after delivery. Similar findings were reported in the eight-state evaluation; for example, just 26 percent of ASHAs recognised foul-smelling vaginal discharge as a danger signal during the postpartum period and 34 
percent knew that a newborn should not be bathed immediately (Ministry of Health and Family Welfare, 2011b).

Finally, issues with regard to incentive payments to ASHAs and their supervision also remain. The eight-state evaluation observes that performancebased payments to ASHAs are poorly implemented in several states and that much of the weaknesses of the ASHA programme can be attributed to the weak support structure (Ministry of Health and Family Welfare, 2011b). The five-state evaluation, likewise, notes that over three-quarters of ASHAs expressed a need for support from ANMs (UNFPA, 2009).

In short, while the ASHA programme has, by and large, been positively assessed, several concerns remain. There is a need to better understand, from the perspectives of ASHAs, their confidence in performing the tasks assigned to them, their perceived credibility with women and their families, their perceptions about their ability to motivate women for institutional delivery, the difficulties they face in conducting the tasks assigned to them, and the kinds of supportive supervision they require to effectively perform these tasks.

\section{Study objectives}

The study aimed to better understand the perceptions and experiences of ASHAs with regard to the implementation of the JSY. Specifically, the objectives of the study were to explore:

- Awareness of the JSY among ASHAs

- The extent of training and supportive supervision that ASHAs had received for performing the tasks assigned to them as part of the JSY

- The competence of ASHAs in carrying out the tasks assigned to them
- The extent to which ASHAs had performed the tasks assigned to them

- The perceptions of ASHAs about the potential of the JSY to improve the maternal and newborn health situation.

\section{Study setting}

The study was conducted in the state of Rajasthan. With a population of 68.6 million in 2011, the state ranked eighth in terms of total population among states in India (Office of the Registrar General and Census Commissioner, India, 2011). With a child sex ratio of 883 females per 1,000 males in 2011, it registered one of the most skewed sex ratios in the country. The state lags behind the rest of India in terms of social and health indicators as well. For example, its overall literacy rate was 67 percent in 2011 compared to 74 percent nationally (Office of the Registrar General and Census Commissioner, India, 2011). Further, with 65 percent of 20-24 year-old women married before age 18 , it ranks second among all states in India in terms of the prevalence of early marriage (International Institute for Population Sciences and Macro International, 2008). Moreover, childbearing in adolescence is widely prevalent in the state; two-fifths of currently married girls aged 15-19 years were already mothers and another one-tenth were pregnant at the time of the survey.

The state's performance in the health sector has also been poor. With a maternal mortality ratio of 318 per 100,000 live births, it records the third highest maternal mortality ratio among all states in India (Office of the Registrar General, India, 2011). Moreover, the utilisation of maternal health services is limited (see Table 1.1). A recent assessment, conducted in 2009-10, also reaffirms that the utilisation of these services is far from 


\section{Table 1.1}

Profile of the study districts and Rajasthan state

\begin{tabular}{|c|c|c|c|}
\hline Characteristics & Alwar District & Jodhpur district & Rajasthan State \\
\hline Population $^{1}$ & $3,671,999$ & $3,685,681$ & $68,621,012$ \\
\hline Overall sex ratio $(\mathrm{F} / \mathrm{M})^{1}$ & 894 & 915 & 926 \\
\hline Child sex ratio $(0-6$ years $)(F / M)^{1}$ & 861 & 890 & 883 \\
\hline Male literacy $(\%)^{1}$ & 85.1 & 80.1 & 80.5 \\
\hline Female literacy $(\%)^{1}$ & 56.8 & 52.6 & 52.7 \\
\hline $\begin{array}{l}\text { Of those married in the last three years, } \\
\text { females married before age } 18(\%)^{2}\end{array}$ & 40.7 & 40.6 & 39.9 \\
\hline $\begin{array}{l}\text { Married women aged } 15-49 \text { currently using } \\
\text { any contraceptive method }(\%)^{2}\end{array}$ & 61.2 & 51.7 & 58.1 \\
\hline $\begin{array}{l}\text { Married women aged } 15-49 \text { who reported } \\
\text { skilled attendance at last delivery }(\%)^{2}\end{array}$ & 51.8 & 47.4 & 52.6 \\
\hline
\end{tabular}

satisfactory -55 percent of women had three or more antenatal check-ups and 70 percent had delivered in a health facility (UNICEF, 2010). The coverage of centrally-sponsored programmes, like the JSY, to promote maternal health, also remains far from universal. For example, an evaluation conducted by the UNFPA reports that just onehalf of women who had delivered in the one year preceding the survey had received financial assistance under the JSY (UNFPA, 2009).

Two districts, Alwar and Jodhpur, were purposively selected for the study. These districts represent the state averages in selected socio-demographic and reproductive health indicators such as male and female literacy rates, percentage of girls married below the legal minimum age at marriage, percentage of women who were currently using contraception and percentage of women who had received skilled attendance at delivery. They also represent the eastern (Alwar) and western (Jodhpur) regions of the state. A few key indicators of the study districts are presented in Table 1.1. The study was fielded in both urban and rural areas of the two districts. We note that although ASHAs were originally recruited to serve in the rural areas under the NRHM, states are allowed to select ASHAs in urban areas as link workers (Ministry of Health and Family Welfare, n.d); accordingly, ASHAs have been recruited in the urban areas of both study districts (personal communication, District Programme Manager, Alwar and Jodhpur districts). The selection of villages in rural areas and census enumeration blocks in urban areas within each district was done using a two-stage, stratified systematic random sampling procedure. At the first stage of selection, three rural blocks and two or three urban blocks were selected. The blocks were first explicitly stratified by population size and the percentage of the population belonging to scheduled castes and tribes, and then implicitly stratified by the level of female literacy. The blocks were then selected systematically from the stratified list, with selection probability proportional to size. Six blocks in rural areas and five blocks in urban areas were thus selected for the study. At the second stage, villages in rural areas and census enumeration blocks in urban areas were selected within each selected block, using 
Table 1.2

Coverage of the study

\begin{tabular}{|l|c|c|r|}
\hline Results of interviews & Combined & Urban & Rural \\
\hline Number of ASHAs listed & 172 & 64 & 108 \\
\hline Number of ASHAs successfully interviewed & 150 & 53 & 97 \\
Number of ASHAs not at home/interview postponed & 22 & 11 & 11 \\
Response rate (\%) & 87 & 83 & 90
\end{tabular}

a similar scheme. A total of 196 sampling units were thus selected.

\section{Study design}

The study was conducted between September 2009 and February 2010 as part of a large-scale evaluation of the JSY that comprised a survey of nearly 5,000 women aged below 35 years who had delivered in the one year preceding the interview, and in-depth interviews of selected survey respondents. ASHAs available in the villages and urban wards selected for the survey of women were invited to participate in the study.

A detailed questionnaire was administered to ASHAs who consented to participate in the study. It was translated into the local language, Hindi, pretested and further modified. A data entry package was prepared (using CSPro) that enabled interviewers to conduct interviews and record responses directly onto mini laptops, thus ensuring built-in consistency checks and rapid transmission of data from the field to the Council office. In addition to questions on background characteristics, the questionnaire included detailed questions about the ASHA's awareness of the JSY, perceptions about the JSY, training and supervision received, awareness of maternal and newborn care practices and experience in performing the tasks articulated as part of the JSY.
Interviewers were recruited locally. A ten-day training workshop was organised for the larger study to acquaint the interviewers with the method of conducting computer-assisted personal interviews, the questionnaire and interview guidelines. Data received from the field were regularly checked for quality and feedback was provided to the investigators.

It was noted that 79 of the 96 villages and 54 of the 100 urban wards included in the study were served by ASHAs. A total of 172 ASHAs were listed in these settings; of these, 150 were successfully interviewed. While no ASHA who was contacted refused to participate in the study, some 13 percent of ASHAs were not interviewed as they could not be contacted even after three home visits. The survey data were analysed using SPSS.

\section{Characteristics of respondents}

The socio-demographic characteristics of the ASHAs who were interviewed are summarised in Table 1.3. On average, the respondents were 29 years of age, with urban respondents being older than rural respondents (31 years versus 28 years). The majority of ASHAs had completed nine years of schooling, with little rural-urban differences. They had been working as an ASHA, on average, for 2.4 years; rural respondents having worked for a slightly longer period than their urban counterparts 
Table 1.3

Socio-demographic characteristics of respondents

\begin{tabular}{|l|c|c|c|}
\hline Characteristics & $\begin{array}{c}\text { Combined } \\
\mathbf{N}=150\end{array}$ & $\begin{array}{c}\text { Urban } \\
\text { N=53 }\end{array}$ \\
\hline Mean age (years) & 29.3 & 31.2 & 28.2 \\
\hline Mean years of schooling & 9.1 & 9.6 & 8.9 \\
\hline Mean years of working as an ASHA & 2.4 & 1.7 & 2.8 \\
\hline Resides in the village/ward (\%) & 91.3 & 79.2 & 97.9 \\
\hline Currently married (\%) & 93.3 & 84.9 & 97.9 \\
\hline
\end{tabular}

(2.8 years versus 1.7 years). Almost all the rural respondents resided in the study villages, while only four-fifths of those in the urban areas resided in the study wards. All the respondents were ever married, with more rural than urban respondents being currently married (98\% versus $85 \%$ ).

\section{Structure of the report}

The report is structured as follows. Chapter 2 examines the awareness of the JSY among ASHAs. Chapter 3 describes the extent to which ASHAs were trained to perform the tasks articulated as part of the
JSY and received supportive supervision from such health functionaries as ANMs. Chapter 4 examines the competencies of ASHAs in performing the tasks assigned to them by assessing their awareness of maternal and newborn care practices; complications experienced by women during pregnancy, delivery and the postpartum period, and by newborns, as well as of family planning methods. Chapter 5 describes the services extended by ASHAs to women in their community, particularly pregnant and recently-delivered women. Chapter 6 summarises the main findings of the study, and presents programme recommendations. 


\section{CHAPTER 2}

\section{Awareness of the JSY among ASHAs}

Given the prominent role of ASHAs in facilitating women to access JSY benefits, the study made a detailed probe into their awareness about the JSY. Specifically, it assessed the extent to which ASHAs were aware of the criteria under which women can avail of JSY benefits, the benefits to which women and ASHAs are entitled and the kinds of support that the ASHA is expected to provide.

\section{Awareness of eligibility conditions for availing of the JSY}

Findings, presented in Table 2.1, indicate that the vast majority of ASHAs were aware of most of the conditions under which women are eligible for receiving JSY benefits. With regard to awareness of the type of facility where women could deliver in order to avail of JSY benefits, 90 percent or more of ASHAs knew that a woman delivering in a government health facility or an accredited private facility is eligible for such benefits. However, just seven percent of ASHAs-13 percent in urban areas and four percent in rural areas-were aware of an accredited private health facility, although the study districts had some 11 such facilities (not shown in table). Fewer than 10 percent of ASHAs knew that a woman delivering at home is eligible for JSY benefits if she is aged 19 and above, belongs to a BPL household and is having her first or second delivery. This is not surprising given that there have been few communication efforts to inform the community at large about women's entitlement to receive some cash benefits for home deliveries under certain conditions. Rural-urban differences were evident; for example, more urban than rural ASHAs knew that deliveries in accredited private facilities are eligible for JSY benefits (100\% versus $86 \%$ ), while more rural than urban ASHAs knew that home deliveries under selected conditions are eligible for JSY benefits (10\% versus $2 \%)$.

The stipulation that women can avail of JSY benefits irrespective of their age, parity and household economic status was also widely known. For example, almost all ASHAs (98\%) knew that a woman delivering in a health facility is eligible for JSY benefits even if she is rich, 87 percent knew that she can avail of JSY benefits for any number of births and 73 percent knew that she can do so regardless of her age. Rural-urban differences were notable with regard to percentages of ASHAs who were aware that women could access JSY benefits regardless of their parity and age, with a larger proportion of rural than urban ASHAs reporting so $(95 \%$ versus $74 \%$ and $78 \%$ versus $62 \%$, respectively).

Awareness of the type of government health facility where women could deliver to obtain JSY benefits was also widespread. For example, 85-100 percent of ASHAs knew that deliveries in Primary Health Centres (PHC), Community Health Centres (CHC) and district hospitals are eligible for JSY benefits. However, only one-fifth of ASHAs knew that deliveries in a normal sub-centre, that is, a subcentre that is not accredited to conduct deliveries, are ineligible for JSY benefits. Rural-urban differences were notable; a larger proportion of ASHAs in rural than urban areas reported such awareness. 


\section{Table 2.1}

Percentage of ASHAs reporting correct awareness of eligibility conditions for availing of the JSY, according to residence

\begin{tabular}{|c|c|c|c|}
\hline ASHAs who knew that: & $\begin{array}{l}\text { Combined } \\
\mathrm{N}=150\end{array}$ & $\begin{array}{l}\text { Urban } \\
\mathbf{N}=53\end{array}$ & $\begin{array}{l}\text { Rural } \\
\mathbf{N}=97\end{array}$ \\
\hline $\begin{array}{l}\text { A woman delivering in a government health facility is } \\
\text { eligible for JSY benefits }\end{array}$ & 100.0 & 100.0 & 100.0 \\
\hline $\begin{array}{l}\text { A woman delivering in an accredited private facility is } \\
\text { eligible for JSY benefits }\end{array}$ & 93.3 & 100.0 & 85.7 \\
\hline $\begin{array}{l}\text { A woman delivering at home is eligible for JSY } \\
\text { benefits, if she meets selected conditions }{ }^{\mathrm{a}}\end{array}$ & 7.3 & 1.9 & 10.3 \\
\hline $\begin{array}{l}\text { A woman delivering in an accredited government or } \\
\text { private health facility is eligible for JSY benefits } \\
\text { even if she is rich }\end{array}$ & 98.0 & 100.0 & 96.9 \\
\hline $\begin{array}{l}\text { A woman delivering in an accredited government or } \\
\text { private health facility can avail of JSY benefits for } \\
\text { any number of births }\end{array}$ & 87.3 & 73.6 & 94.8 \\
\hline $\begin{array}{l}\text { A woman delivering in an accredited government } \\
\text { or private health facility can avail of JSY benefits } \\
\text { regardless of her age }\end{array}$ & 72.7 & 62.3 & 78.4 \\
\hline $\begin{array}{l}\text { Deliveries occurring in a normal, that is, a non- } \\
\text { accredited sub-centre }{ }^{\mathrm{b}} \text { are ineligible for JSY benefits }\end{array}$ & 22.0 & 9.4 & 28.9 \\
\hline $\begin{array}{l}\text { Deliveries occurring in a primary health centre are } \\
\text { eligible for JSY benefits }\end{array}$ & 86.0 & 64.2 & 97.9 \\
\hline $\begin{array}{l}\text { Deliveries occurring in a community health centre are } \\
\text { eligible for JSY benefits }\end{array}$ & 84.7 & 58.5 & 99.0 \\
\hline $\begin{array}{l}\text { Deliveries occurring in a district hospital are eligible } \\
\text { for JSY benefits }\end{array}$ & 100.0 & 100.0 & 100.0 \\
\hline
\end{tabular}

Note: "If the woman is aged 19 and above, belongs to a BPL household and is having her first or second delivery; ${ }^{b}$ As per the JSY guidelines, deliveries conducted in sub-centres accredited by the stateldistrict authorities are considered as institutional deliveries and therefore, women delivering in these centres are eligible for cash assistance under the JSY. Accredited sub-centres are those that are located in government buildings with such facilities as electricity, water and other medical requirements for basic obstetric services including drugs, equipment and services of trained midwives for the purpose of conducting normal deliveries.

\section{Awareness of entitlements of beneficiaries and ASHAs under the JSY}

Awareness of the monetary and non-monetary support to which women are entitled under the JSY was somewhat limited among ASHAs (Figure 2.1). For example, only 71 percent of ASHAs knew that a woman who delivers in a government or an accredited private facility is entitled to Rs. 1,400 in rural areas and Rs. 1,000 in urban areas. ASHAs in urban areas were more likely than those in rural areas to report so (83\% versus 65\%). Even fewer (23\%) knew that women delivering at home who meet selected conditions are entitled to Rs. 500; ASHAs in rural areas were more likely than their urban counterparts to be aware of this entitlement (30\% versus $11 \%$ ). Likewise, only 55 percent, 65 percent and 37 percent of ASHAs knew that women are entitled to receive support from ASHAs during the antenatal period, delivery and the postpartum 
Figure 2.1: Awareness of ASHAs about women's monetary and non-monetary entitlements under the JSY, according to residence

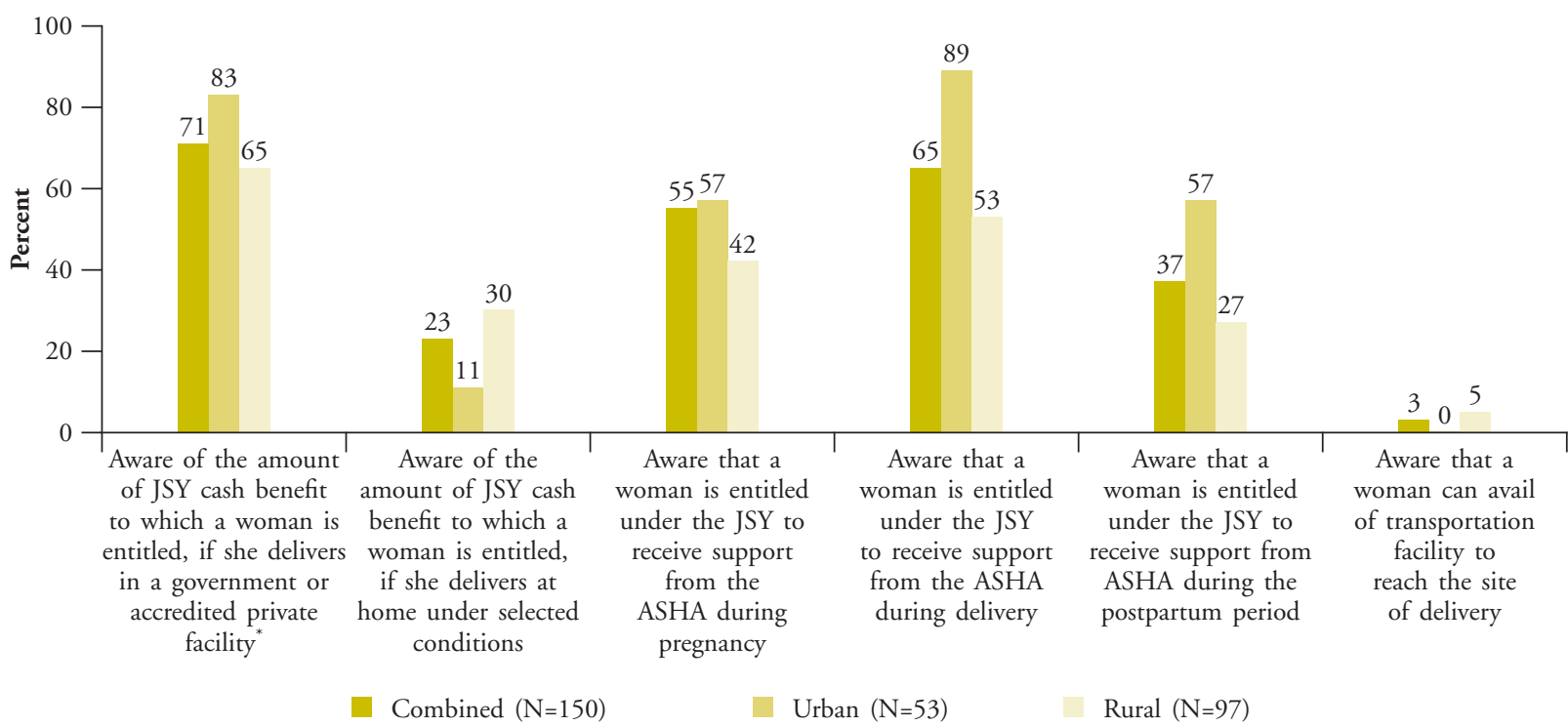

Note: ${ }^{*}$ Those who reported Rs. 1,400 for rural women and Rs. 1,000 for urban women were considered as having correct awareness.

period, respectively. ASHAs in urban areas were more likely than their rural counterparts to be so informed.

Findings, illustrated in Figure 2.2, indicate considerable confusion among ASHAs with regard to their own entitlements for supporting women to avail of JSY benefits. Thus, only 11 percent and 39 percent of ASHAs reported that ASHAs who assist pregnant women to access maternal health services, particularly institutional delivery, are provided an incentive of Rs. 600/woman and Rs. 200/woman in rural and urban areas, respectively. The remaining ASHAs reported amounts ranging from Rs. 100 to Rs. 500, perhaps because the amount stipulated in the scheme is apportioned for different activities.

\section{Awareness of the ASHA's responsibilities under the JSY}

As mentioned earlier, the JSY entrusts ASHAs with a number of responsibilities to enable pregnant women
Figure 2.2: Awareness of ASHAs about their own entitlements under the JSY, according to residence

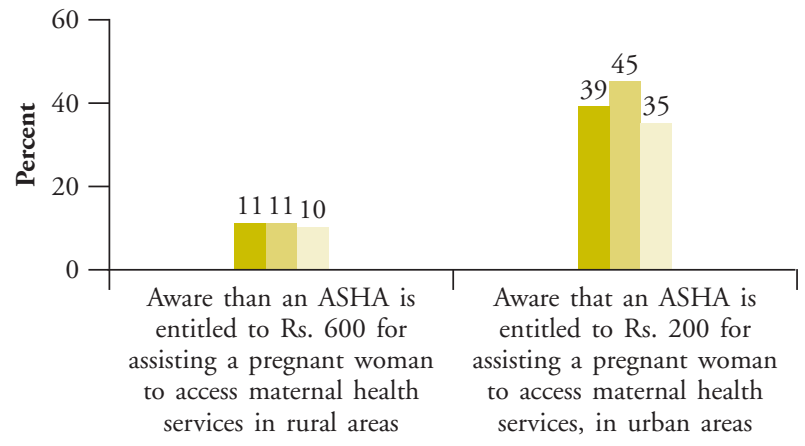

Combined $(\mathrm{N}=150) \quad$ Urban $(\mathrm{N}=53) \quad$ Rural $(\mathrm{N}=97)$

to avail of maternal and child health services and related JSY benefits (Ministry of Health and Family Welfare, 2006). The study assessed the extent to which ASHAs were aware of these responsibilities; the findings present a mixed picture (Table 2.2).

Responsibilities such as assisting pregnant women to register for antenatal check-ups and seek 


\section{Table 2.2}

Percentage of ASHAs reporting awareness of their responsibilities under the JSY, according to residence

\begin{tabular}{|c|c|c|c|}
\hline $\begin{array}{l}\text { ASHAs who knew that their responsibilities under the } \\
\text { JSY included }\end{array}$ & $\begin{array}{l}\text { Combined } \\
\mathrm{N}=150\end{array}$ & $\begin{array}{l}\text { Urban } \\
\mathrm{N}=53\end{array}$ & $\begin{array}{l}\text { Rural } \\
\mathbf{N}=97\end{array}$ \\
\hline $\begin{array}{l}\text { Assisting pregnant women to register for antenatal } \\
\text { services }{ }^{1}\end{array}$ & 96.7 & 98.1 & 95.9 \\
\hline $\begin{array}{l}\text { Assisting pregnant women to access three antenatal } \\
\text { check-ups }\end{array}$ & 97.3 & 96.2 & 97.9 \\
\hline Counseling pregnant women about institutional delivery ${ }^{1}$ & 100.0 & 100.0 & 100.0 \\
\hline $\begin{array}{l}\text { Informing pregnant women about an eligible } \\
\text { government/private health facility for delivery }\end{array}$ & 96.7 & 96.2 & 96.9 \\
\hline $\begin{array}{l}\text { Arranging transport for women to reach a health facility } \\
\text { for delivery }{ }^{1}\end{array}$ & 85.3 & 66.0 & 95.9 \\
\hline Escorting women to a health facility for delivery ${ }^{1}$ & 100.0 & 100.0 & 100.0 \\
\hline $\begin{array}{l}\text { Staying with women till they are discharged from the } \\
\text { health facility after the delivery }\end{array}$ & 56.0 & 39.6 & 64.9 \\
\hline $\begin{array}{l}\text { Making postpartum visits to women within seven days of } \\
\text { delivery }{ }^{1}\end{array}$ & 99.3 & 100.0 & 99.0 \\
\hline Counseling recently-delivered women about breastfeeding & 52.0 & 49.1 & 53.6 \\
\hline $\begin{array}{l}\text { Counseling recently-delivered women about family } \\
\text { planning }\end{array}$ & 5.3 & 9.4 & 3.1 \\
\hline Arranging immunisation of the newborn & 94.0 & 92.5 & 94.0 \\
\hline
\end{tabular}

Note: 'Spontaneous or prompted responses; others are spontaneous responses.

three antenatal check-ups, counseling them about institutional delivery, assisting them to identify a health facility for delivery, escorting them to the pre-determined health facility for delivery, making postpartum visits within seven days of the woman's delivery and arranging immunisation services for newborns were almost universally known. Tasks such as arranging transport to reach the health facility for delivery were also widely known, with 85 percent of ASHAs reporting it as their responsibility. However, such tasks as staying with the women till they are discharged from the health facility after delivery and counseling them about breastfeeding were much less known (reported by 52-56 percent of ASHAs) while counseling recently-delivered women about family planning was rarely known, as the ASHA's responsibility (reported by just 5\% percent of ASHAs). Rural-urban differences were largely narrow. Even so, ASHAs in rural areas were more likely than those in urban areas to report such tasks as arranging transport, staying with the pregnant woman till she is discharged from the health facility after delivery and counseling her about breastfeeding as the ASHA's responsibilities.

\section{Awareness of schemes other than the JSY}

The study also included questions to assess the awareness of ASHAs regarding schemes other than the JSY intended to promote safe motherhood, such as the 108 ambulance service and the special nutritional supplementation scheme (namely, the 
Figure 2.3: Awareness of schemes other than the JSY among ASHAs, according to residence

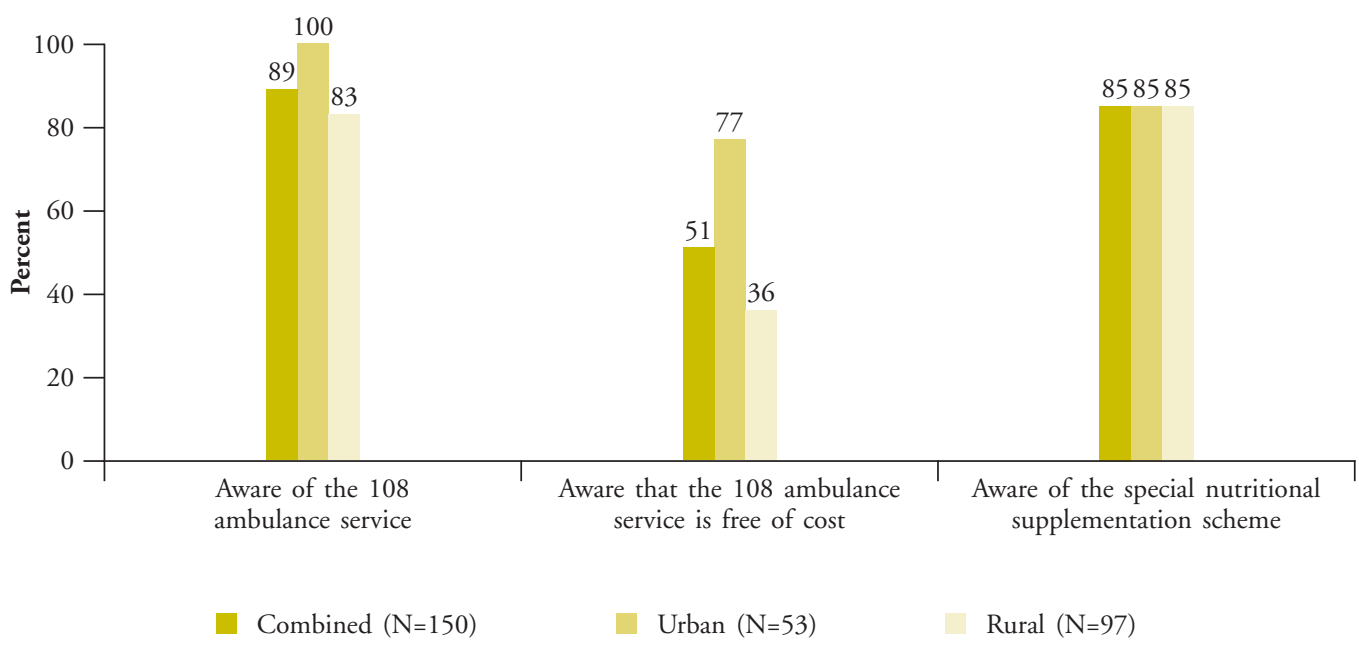

provision of 5 kilograms of ghee to recentlydelivered women). Findings, depicted in Figure 2.3 , indicate that nine in ten ASHAs were aware of the ambulance service, with more urban than rural ASHAs reporting so (100\% versus $83 \%)$. However, somewhat fewer $(51 \%)$ were aware that the ambulance service is free of cost, with twice as many urban as rural ASHAs reporting so $(77 \%$ versus $36 \%)$. Finally, $85 \%$ of ASHAs, regardless of rural-urban residence, had heard about the special nutritional supplementation scheme. 


\section{CHAPTER 3}

\section{Extent of training and supportive supervision received by ASHAs}

The study also included questions to assess the extent to which the ASHAs were trained to perform the tasks articulated as part of the JSY and received supportive supervision from such health functionaries as ANMs.

\section{Training received by ASHAs in imparting information on sexual and reproductive matters}

We assessed whether the ASHAs who participated in the study had received training in imparting information on sexual and reproductive matters that are covered in the ASHA training modules. We note that our study did not specifically probe about whether training sessions on each of the various modules contained in the ASHA training manual had been organised in the study area; whether ASHAs had attended such training workshops, if organised; and among those who participated in training workshops, the exact modules to which they had been exposed. Hence, our findings, presented in Table 3.1, need to be interpreted with some caution. Findings show that over 90 percent of ASHAs had received training in imparting information on such topics as contraception, care during pregnancy, delivery and the postpartum period, and newborn care. Rural-urban differences were narrow.

ASHAs were also asked whether IEC materials on sexual and reproductive matters were available to them and whether they had ever used them for imparting information on these topics. Findings indicate that the vast majority $(78-87 \%)$ of ASHAs reported that IEC materials were generally available on such topics as contraception, care during pregnancy, delivery and the postpartum period, and newborn care. Almost nine out of ten ASHAs reported the availability of IEC materials on at least one of these topics (Table 3.2). Rural-urban differences indicate that ASHAs in rural areas were more likely than their urban counterparts to report

\section{Table 3.1}

Percentage of ASHAs who had received training in imparting information on sexual and reproductive matters, according to residence

\begin{tabular}{|l|c|c|c|}
\hline Topics on which training was received & $\begin{array}{c}\text { Combined } \\
\mathbf{N = 1 5 0}\end{array}$ & Urban & $\begin{array}{c}\text { Rural } \\
\text { N=97 }\end{array}$ \\
\hline Contraception & 94.7 & 96.2 & 93.8 \\
\hline Care during pregnancy & 95.3 & 96.2 & 94.8 \\
\hline Care during delivery & 93.3 & 94.3 & 92.8 \\
\hline Care during the postpartum period & 96.0 & 94.3 & 96.9 \\
\hline Newborn care & 99.3 & 100.0 & 99.0 \\
\hline
\end{tabular}


the availability of IEC materials on contraception (81\% versus $72 \%)$ and care during pregnancy (88\% versus $77 \%)$. Further, almost three-quarters of ASHAs reported that these materials were easily accessible; more rural than urban ASHAs so reported (75\% versus 66\%). While four-fifths of ASHAs reported that the existing IEC materials were appropriate for meeting their needs, some 82 percent said that they had used these materials to impart information; rural-urban differences were narrow.

\section{Supportive supervision received by ASHAs}

ASHAs are also expected to maintain regular contact with ANMs and medical officers of primary health centres. The study, therefore, covered a number of questions to assess the extent to which ASHAs received supportive supervision from ANMs. Findings, presented in Figure 3.1, suggest that the extent of supervision received by ASHAs was far

Table 3.2

Percentage of ASHAs reporting availability and use of IEC materials on sexual and reproductive topics

\begin{tabular}{|l|c|c|c|}
\hline Topics on which IEC materials were available & Combined & Urban & $\begin{array}{c}\text { Rural } \\
\text { N=97 }\end{array}$ \\
\hline Contraception & $\mathbf{N}=\mathbf{1 5 0}$ & 81.4 \\
\hline Care during pregnancy & 78.0 & 71.7 & 87.6 \\
\hline Care during delivery & 84.0 & 77.4 & 85.6 \\
\hline Care during the postpartum period & 84.0 & 81.1 & 85.6 \\
\hline Newborn care & 84.0 & 81.1 & 86.6 \\
\hline At least one of the above topics & 86.7 & 86.8 & 88.7 \\
\hline Perceptions about and use of IEC materials & 88.0 & 86.8 & \\
\hline IEC materials are easily accessible & & & 75.3 \\
\hline IEC materials are appropriate to meet the needs of ASHAs & 78.7 & 79.0 & 79.4 \\
\hline Ever used IEC materials to impart information & 81.6 & 82.0 & 79.2 \\
\hline
\end{tabular}

Figure 3.1: Percentage of ASHAs reporting having received supportive supervision from ANMs, according to residence

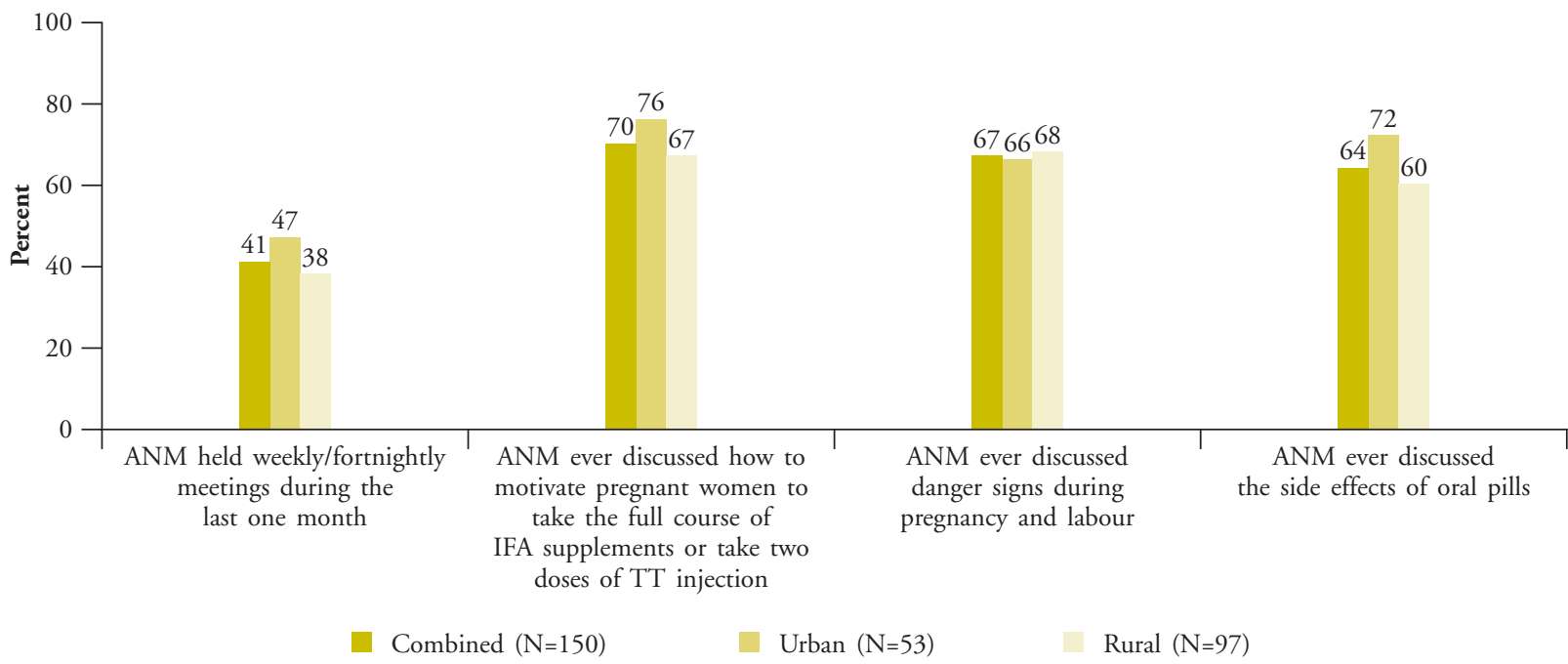


from satisfactory. For example, just two-fifths of ASHAs reported that the ANM had held weekly or fortnightly meetings with them in the one month preceding the survey; ASHAs in rural areas were less likely than their urban counterparts to report so (38\% versus $47 \%$ ). Likewise, efforts by ANMs to build the skills of ASHAs were somewhat limited. For example, 70 percent of ASHAs reported that an ANM had ever discussed with them how to motivate pregnant women to complete the full course of IFA supplements or to take two doses of TT injection, with urban ASHAs somewhat more likely than their rural counterparts to report so (76\% versus $67 \%$ ). Two-thirds of ASHAs, regardless of rural-urban residence, reported that an ANM had ever discussed the danger signs during pregnancy and labour with them. A similar percentage of ASHAs reported that an ANM had ever discussed the side effects of oral pills with them; urban ASHAs were more likely than the rural to report so $(72 \%$ versus $60 \%)$.

\section{Confidence at work among ASHAs and their perceived credibility}

The study also included questions to assess the confidence of ASHAs in performing the tasks assigned to them as well as their perceived credibility with women in the community they served. Specifically, the ASHAs were asked whether they felt comfortable in discussing pregnancy-related matters with women in their community and
Figure 3.2: Confidence at work among ASHAs and their perceived credibility, according to residence

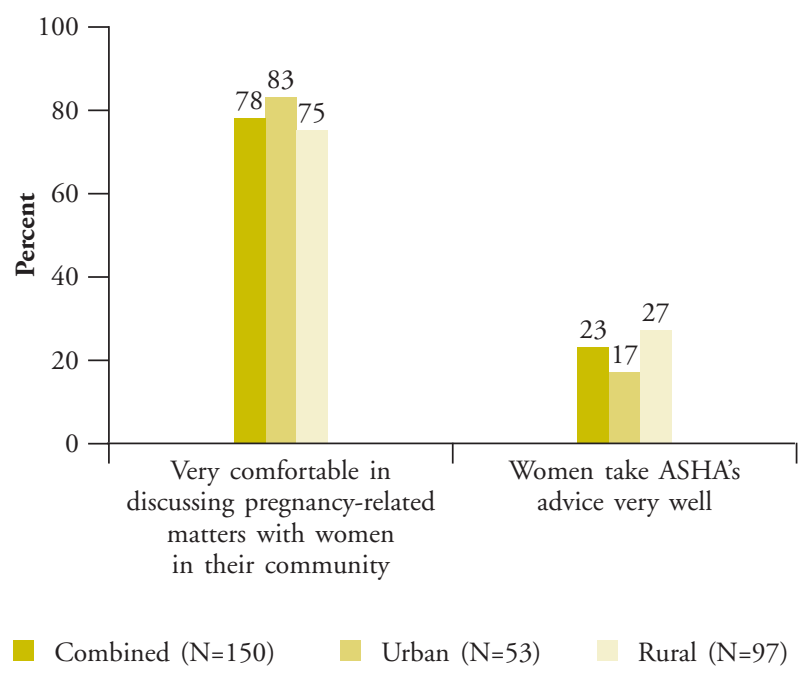

whether women listened to their advice. Findings, illustrated in Figure 3.2, suggest that most ASHAs were confident about performing the tasks assigned to them. For example, three-quarters of ASHAs said that they felt very comfortable in discussing pregnancy-related matters with women in their community; ASHAs in urban areas were somewhat more likely than their rural counterparts to report so $(83 \%$ versus $75 \%)$. However, most ASHAs perceived that their credibility with women in their community is low. For example, only one-quarter of ASHAs felt that women took their advice seriously; ASHAs in rural areas were more likely than those in urban areas to report so (27\% versus $17 \%)$. 


\section{Awareness of maternal and newborn care practices among ASHAs}

Several questions were posed to elicit the awareness of maternal and newborn care practices among ASHAs. The questions covered five themes, namely, awareness of antenatal care practices; awareness of birth preparedness matters; awareness of postpartum care practices; awareness of newborn care practices; and awareness of complications during pregnancy, delivery and the postpartum period, and complications experienced by newborns.

\section{Awareness of antenatal care practices}

ASHAs who participated in the study were probed about their awareness of the number of antenatal check-ups that a woman should have; the appropriate timing of the first, second and third check-ups, the number of doses of TT injection she should receive and the number of days that she should take IFA supplements. A summary measure of comprehensive awareness of antenatal care practices indicating the percentage of ASHAs who were aware of all of the above practices was also constructed.

Awareness of the number of antenatal check-ups, the number of doses of TT injection and number of days that IFA supplements should be taken was almost universal as shown in Figure 4.1; 94-97 percent of ASHAs, regardless of rural-urban residence, were aware of all three practices. However, awareness of the appropriate timing of essential antenatal checkups was somewhat limited; three-quarters of ASHAs

Figure 4.1: Awareness of antenatal care practices among ASHAs, according to residence

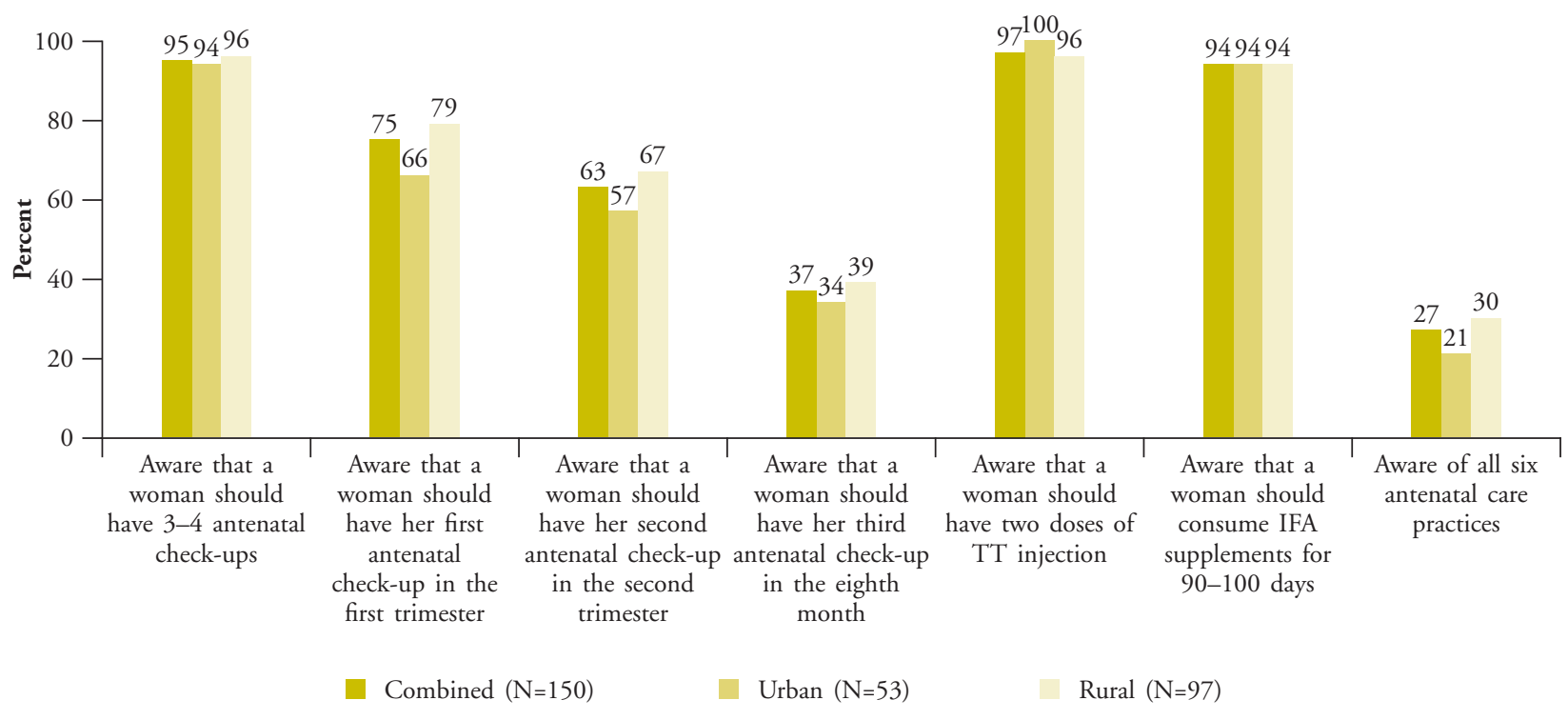


knew that a woman should have her first antenatal check-up in the first trimester, about two-thirds knew that she should have her second antenatal check-up in the second trimester, and about two-fifths that she should have her third antenatal check-up in the eighth month. ASHAs in rural areas were more likely than their urban counterparts to be correctly informed about the timing of these antenatal checkups. Findings, moreover, highlight that just onequarter of ASHAs had comprehensive awareness of antenatal care practices, with rural ASHAs being more likely than their urban counterparts to display such awareness.

\section{Awareness of birth preparedness matters}

The study explored the awareness of birth preparedness among ASHAs by asking them to name the essential preparations that a woman should make for a safe delivery. All those who reported that a woman should identify a hospital or trained midwife for delivery, make arrangements for transportation, save money for delivery expenses, identify a referral health facility to go to in case of an emergency or keep items for safe delivery in case she opts for a home delivery were considered to have some awareness of birth preparedness.

Findings, illustrated in Figure 4.2, indicate that the majority of ASHAs were aware of some of the essential birth preparation indicators; for example, three-quarters identified making arrangements for transportation, two-thirds identified saving money for delivery expenses and one-half mentioned identifying a hospital or trained midwife for delivery as being essential for a safe delivery. Two-fifths of ASHAs were aware of three or more preparations for a safe delivery. ASHAs in urban areas were better informed about birth preparedness matters than their rural counterparts.

\section{Awareness of postpartum care practices}

The study also assessed whether or not ASHAs were aware that a woman should have a postpartum check-up even if she is feeling well, that a woman should have her first postpartum check-up within a few hours or, at best, within two days of delivery and that a woman should have at least three

Figure 4.2: Awareness of birth preparedness among ASHAs, according to residence

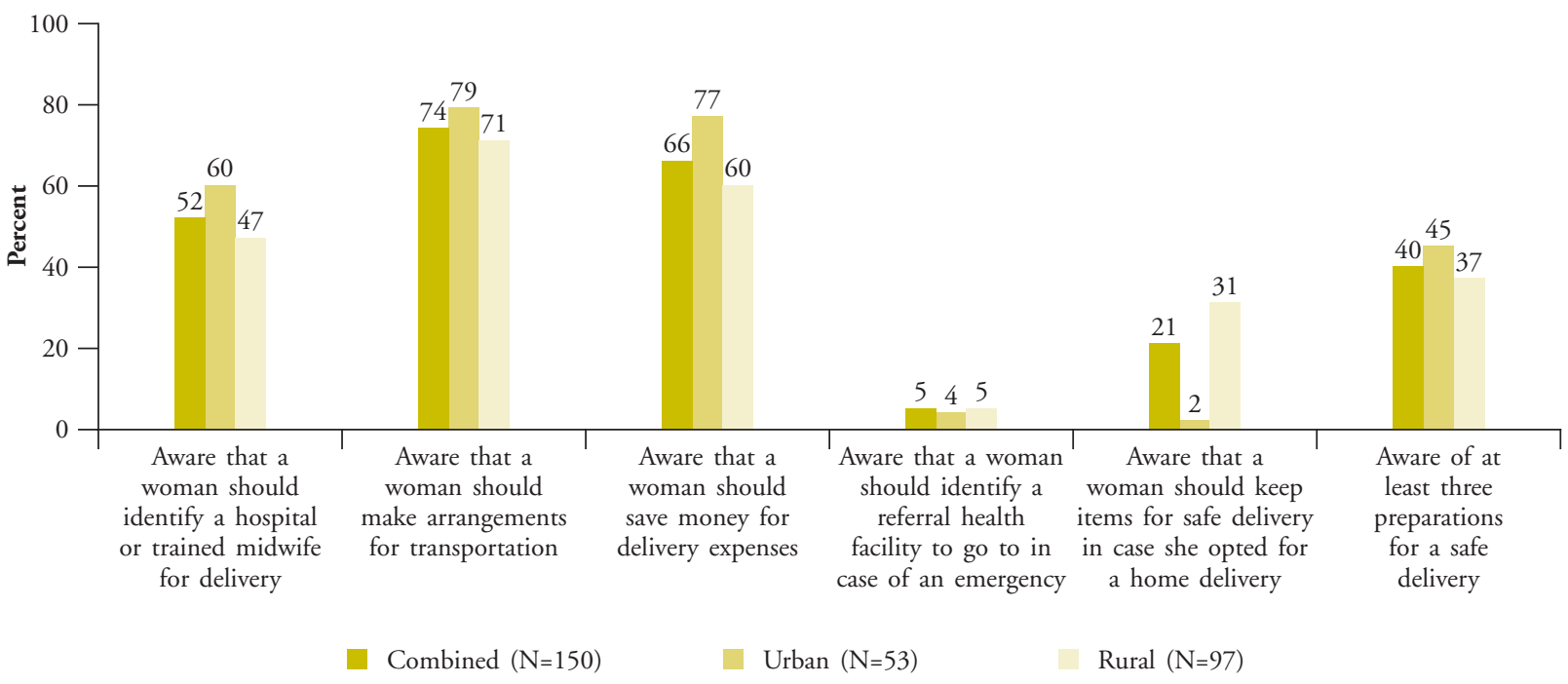


postpartum check-ups. A summary indicator of comprehensive awareness of postpartum care practices as measured by the percentage of ASHAs who were aware of all three issues was also calculated.

Findings, presented in Figure 4.3, show that nine out of ten ASHAs knew that a woman should have a postpartum check-up even if she is feeling fine. Fewer knew that a woman should have her first check-up within a few hours or, at best, within two days of delivery $(63 \%)$ and even fewer that a woman should have three postpartum check-ups (27\%). Just one-fifth of ASHAs displayed comprehensive awareness of postpartum care practices. Rural-urban differences were, by and large, modest.

\section{Awareness of newborn care practices}

The study also explored the awareness of ASHAs with regard to several dimensions of newborn care practices, including the immediate care of the newborn, breastfeeding practices and immunisation. To assess their awareness of immediate newborn care practices, the study assessed whether the ASHAs knew that a newborn should be wiped dry and not bathed immediately after birth and that it is not good to apply any substance on the cord stump. A summary indicator of comprehensive awareness of best practices regarding immediate newborn care, reflected by the percentage of ASHAs who were knowledgeable about both these aspects, was also calculated. In the area of feeding practices, the study assessed whether the ASHAs were aware that a newborn should be breastfed within an hour of delivery, fed colostrum, exclusively breastfed for six months and offered complementary food at six months of age. An indicator of comprehensive awareness of feeding practices as measured by the percentage of ASHAs aware of all four aspects was also calculated. To assess their awareness of immunisation of newborns, the ASHAs were asked about the number of doses of BCG, oral polio, DPT and measles vaccines to be given to an infant as well as the timing of administering the different doses of these vaccines. A summary indicator showing the percentage of ASHAs who were correctly informed about all these aspects of immunisation was also constructed.

Figure 4.3: Awareness of postpartum care practices among ASHAs, according to residence

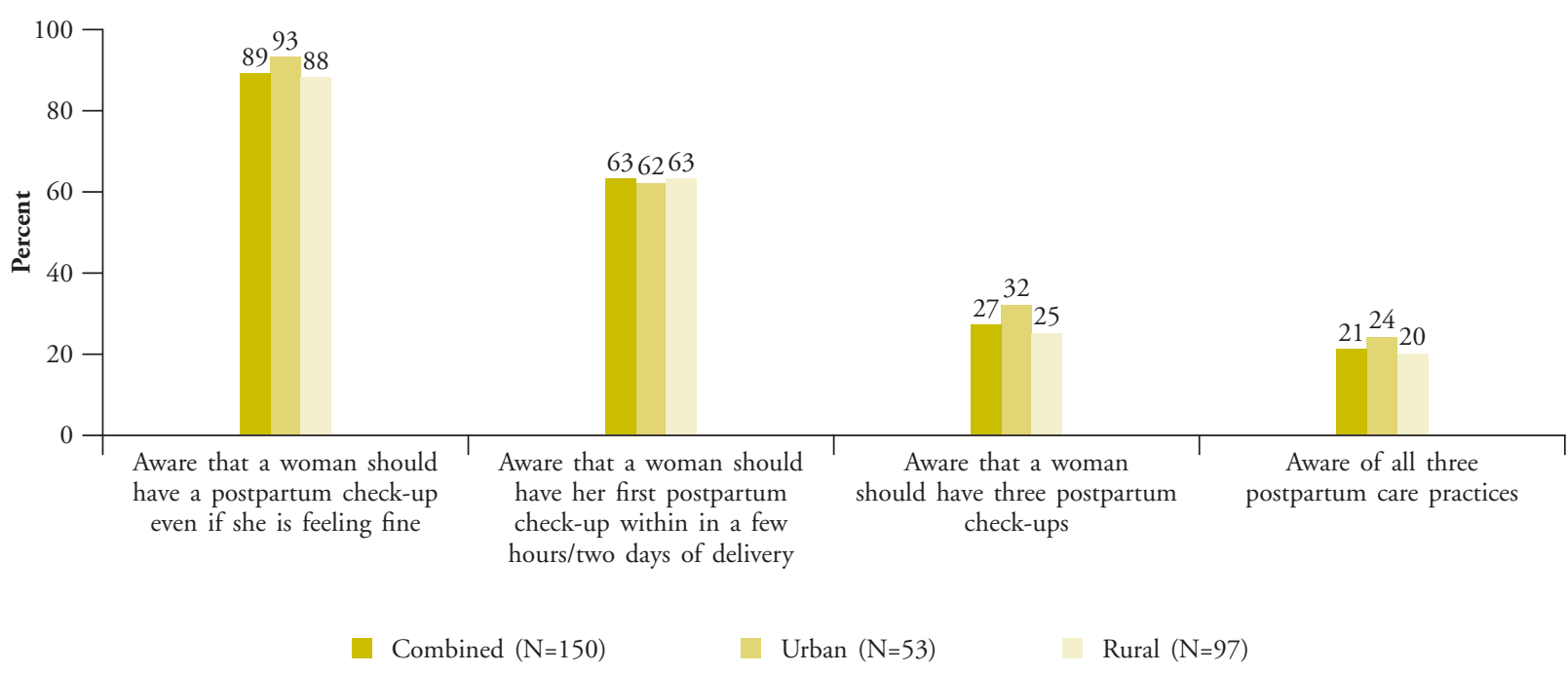


Findings show that the vast majority of ASHAs were aware of the best practices related to immediate newborn care (Table 4.1). For example, 97 percent of ASHAs knew that a newborn should be wiped dry and not be bathed immediately and 83 percent knew that it is not good to apply any substance on the cord stump. Further, a little over fourfifths of ASHAs (82\%) were aware of both these practices; more urban than rural ASHAs reported such comprehensive awareness (89\% versus 78\%). Awareness of appropriate feeding practices, likewise, was high; over 90 percent of ASHAs, regardless of rural-urban residence, knew that a newborn should be breastfed within an hour of delivery, a newborn should be fed colostrum, an infant should be breastfed exclusively for six months and an infant should be offered complementary food at six months of age. Comprehensive awareness of feeding practices was reported by 92 percent of ASHAs; as earlier, ASHAs in urban areas were more likely than their rural counterparts to report such awareness (98\% versus $89 \%)$. Awareness of the immunisation schedule, similarly, was high. Three-quarters or more of ASHAs were correctly informed about the number as well as the timing of different doses of BCG, oral polio, DPT and measles vaccines to be given to a newborn. Almost half of the ASHAs demonstrated comprehensive awareness of the immunisation

\section{Table 4.1}

Percentage of ASHAs reporting awareness of newborn care practices, according to residence

\section{ASHAs who knew that}

A newborn should be wiped dry and not be bathed immediately

It is not good to apply any substance on the cord stump

\section{Comprehensive awareness of best practices related to} immediate care of the newborn

A newborn should be breastfed within an hour of delivery

A newborn should be fed colostrum

An infant should be breastfed exclusively for six months

An infant should be offered complimentary food at six months of age

\section{Comprehensive awareness of feeding practices}

A newborn should be given one dose of BCG vaccine

A newborn should be given BCG vaccination at birth

A newborn should be given the first dose of oral polio vaccine at birth

A newborn should be given the second dose of oral polio vaccine at six weeks

A newborn should be given three doses of DPT vaccine

A newborn should be given the first dose of DPT vaccine at six weeks

A newborn should be given a single dose of measles vaccine

Comprehensive awareness of immunisation
Combined

$\mathrm{N}=150$

97.3

83.3

82.0

88.7

98.1

90.6

79.4

96.7

98.1

99.3

100.0

100.0

100.0

90.7

94.0

98.1

88.7

92.0

94.3

92.8

93.3

86.8

79.4

84.0

88.7

81.4

68.7

77.4

63.9

82.0

90.6

77.3

79.3

88.7

74.2

96.7

96.2

96.9

49.3
43.3 
schedule; again, urban ASHAs were more likely than their rural counterparts to display such awareness (60\% versus $43 \%)$.

\section{Awareness of maternal and newborn complications}

We assessed the awareness of ASHAs with regard to complications during pregnancy in terms of whether they recognised at least one of the selected symptoms - severe headache, blurred vision, high blood pressure, swelling around the ankles, puffiness of the face, fits, high fever, vaginal bleeding, foulsmelling vaginal discharge, jaundice and anaemia - as pregnancy-related complications for which a woman should seek care from a health care provider. Likewise, we assessed whether they recognised at least one of the selected symptoms-abnormal foetal presentation, prolonged labour, obstructed labour, heavy bleeding, fits and retained placenta-as complications of labour and delivery for which a woman should seek care from a health care provider. With regard to awareness of postpartum complications, we assessed whether ASHAs recognised at least one of the selected symptoms — heavy bleeding, high fever, foul-smelling vaginal discharge and fits_-as postpartum complications requiring the attention of a health care provider. Finally, we also assessed whether the ASHAs recognised at least one of the selected symptoms-difficulty in breathing, fast breathing, high fever, difficulty in suckling, stiffness of the body, no bowel movement or urination within 24 hours of birth, infected umbilical cord, diarrhoea and jaundice-as complications in newborns for which care should be sought from a health care provider.

Findings presented in Table 4.2 and Figure 4.4 show that considerable proportions of ASHAs were aware of the complications of pregnancy;

55 percent were able to list at least three of the selected pregnancy complications, with slightly more rural than urban ASHAs reporting so $(58 \%$ versus $51 \%$ ). Anaemia, followed by swelling around the ankles and puffiness of the face, were most frequently cited, while jaundice followed by foul-smelling vaginal discharge, were least frequently cited. Fewer

Figure 4.4: Awareness of three or more maternal and newborn complications among ASHAs, according to residence

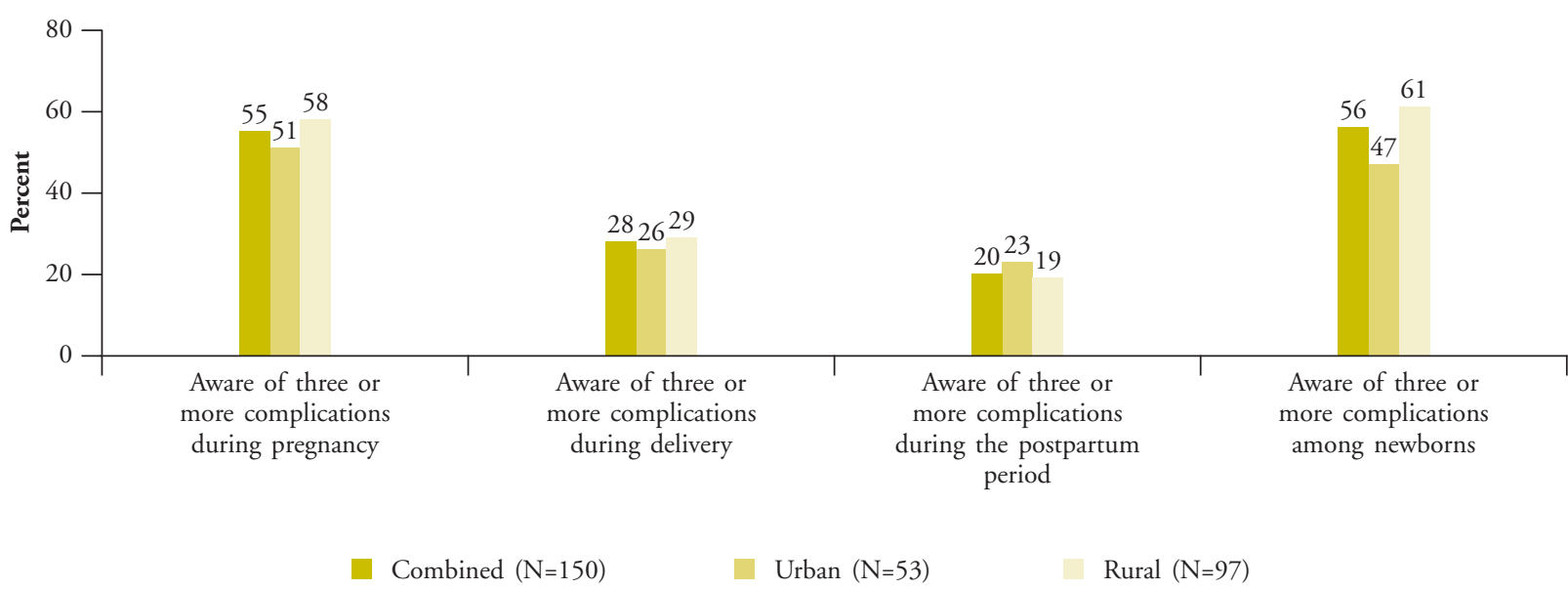




\section{Table 4.2}

Percentage of ASHAs reporting correct awareness of maternal and newborn complications, according to residence

\begin{tabular}{|c|c|c|c|}
\hline ASHAs who recognised the following as complications & $\begin{array}{c}\text { Combined } \\
\mathrm{N}=150\end{array}$ & $\begin{array}{l}\text { Urban } \\
\mathbf{N}=53\end{array}$ & $\begin{array}{l}\text { Rural } \\
\mathbf{N}=97\end{array}$ \\
\hline \multicolumn{4}{|l|}{ During pregnancy } \\
\hline Severe headache/blurred vision/high blood pressure & 30.0 & 30.2 & 29.9 \\
\hline Swelling around the ankles/puffiness of the face & 55.3 & 50.9 & 57.7 \\
\hline Fits & 32.7 & 28.3 & 35.1 \\
\hline High fever & 27.3 & 34.0 & 23.7 \\
\hline Vaginal bleeding & 34.0 & 43.4 & 28.9 \\
\hline Foul-smelling vaginal discharge & 7.3 & 9.4 & 6.2 \\
\hline Jaundice & 10.0 & 5.7 & 12.4 \\
\hline Anaemia & 68.0 & 60.4 & 72.2 \\
\hline Reported three or more of the above & 55.3 & 50.9 & 57.7 \\
\hline \multicolumn{4}{|l|}{ During labour and delivery } \\
\hline Abnormal foetal presentation & 28.7 & 18.9 & 34.0 \\
\hline Labour too long & 38.7 & 41.5 & 37.1 \\
\hline Obstructed labour & 26.7 & 30.2 & 24.7 \\
\hline Fits & 31.3 & 28.3 & 33.0 \\
\hline Heavy bleeding & 59.3 & 52.8 & 62.9 \\
\hline Placenta not coming out & 28.0 & 26.4 & 28.9 \\
\hline Reported three or more of the above & 28.0 & 26.4 & 28.9 \\
\hline \multicolumn{4}{|l|}{ During the postpartum period } \\
\hline Heavy bleeding & 82.0 & 77.4 & 84.5 \\
\hline High fever & 38.7 & 34.0 & 41.2 \\
\hline Foul-smelling vaginal discharge & 24.0 & 24.5 & 23.7 \\
\hline Fits & 26.7 & 32.1 & 23.7 \\
\hline Reported three or more of the above & 20.3 & 22.6 & 18.6 \\
\hline \multicolumn{4}{|l|}{ Among newborns } \\
\hline Difficulty in breathing & 20.7 & 26.4 & 17.5 \\
\hline Fast breathing & 40.7 & 34.0 & 44.3 \\
\hline High fever & 60.7 & 56.6 & 62.9 \\
\hline Difficulty in suckling & 42.0 & 43.4 & 41.2 \\
\hline Stiffness of the body & 11.3 & 13.2 & 10.3 \\
\hline No bowel movement or urination within 24 hours & 17.3 & 9.4 & 21.6 \\
\hline Infected umbilical cord & 16.0 & 17.0 & 15.5 \\
\hline Diarrhoea & 28.7 & 35.8 & 24.7 \\
\hline Jaundice & 18.7 & 22.6 & 16.5 \\
\hline Reported three or more of the above & 56.0 & 47.2 & 60.8 \\
\hline
\end{tabular}


ASHAs were aware of complications during labour and delivery; 28 percent of ASHAs cited three or more danger signs during labour and delivery, with little variation by rural-urban residence. Even fewer were aware of postpartum complications; 20 percent of ASHAs cited three or more danger signs during the postpartum period, again, with little rural-urban variation. With regard to awareness of complications among newborns, the majority of ASHAs cited three or more selected complications, with more rural than urban ASHAs reporting so (61\% versus 47\%).

The study also investigated the awareness of ASHAs regarding appropriate health facilities, that is, those equipped to treat selected pregnancy-related complications such as puffiness of the face and antepartum bleeding, i.e., bleeding occurring after 20 weeks of pregnancy or during labour but before the delivery of the baby. Findings, presented in Table 4.3 , indicate limited awareness of appropriate health facilities for treating pregnancy-related complications.
Findings indicate that sizeable proportions of ASHAs believed that women experiencing selected pregnancy-related complications can be treated in an inappropriate facility, i.e., one that is not equipped to address these complications. For example, $40 \%$ ASHAs reported that a pregnant woman who experiences puffiness of the face can be treated in a sub-centre and $31 \%$ reported that a pregnant woman experiencing antepartum bleeding can be treated in a primary health centre; the recommended lowest level facility for these are a primary health centre and a community health centre, respectively. A larger proportion of ASHAs in rural than urban area perceived that women reporting these complications can be treated in an inappropriate facility $(50 \%$ versus $23 \%$ in the case of puffiness of the face and $47 \%$ versus none in the case of antepartum bleeding). Only 34-35\% of ASHAs reported that women experiencing these complications must go to the recommended facility. A larger proportion of

\section{Table 4.3}

ASHAs' awareness of recommended facilities to which a pregnant woman who experiences selected pregnancy-related complications must go for treatment

\begin{tabular}{|c|c|c|c|c|c|c|}
\hline \multirow{3}{*}{$\begin{array}{l}\% \text { of ASHAs who perceived that } \\
\text { pregnant women experiencing } \\
\text { selected complications can be } \\
\text { treated at }\end{array}$} & \multicolumn{6}{|c|}{ Complications } \\
\hline & \multicolumn{3}{|c|}{$\begin{array}{l}\text { Puffiness of the face } \\
\text { (Recommended: PHC) }\end{array}$} & \multicolumn{3}{|c|}{$\begin{array}{c}\text { Antepartum bleeding } \\
\text { (Recommended: FRU/CHC) }\end{array}$} \\
\hline & $\begin{array}{l}\text { Combined } \\
\mathbf{N}=150\end{array}$ & $\begin{array}{l}\text { Urban } \\
N=53\end{array}$ & $\begin{array}{l}\text { Rural } \\
\mathbf{N}=97\end{array}$ & $\begin{array}{l}\text { Combined } \\
\mathbf{N}=150\end{array}$ & $\begin{array}{l}\text { Urban } \\
\mathbf{N}=53\end{array}$ & $\begin{array}{l}\text { Rural } \\
\mathrm{N}=97\end{array}$ \\
\hline $\begin{array}{l}\text { Inappropriate (a facility not } \\
\text { equipped to address this } \\
\text { problem) }\end{array}$ & 40.0 & 22.6 & 49.5 & 30.7 & 0.0 & 47.4 \\
\hline $\begin{array}{l}\text { Recommended facility (lowest level } \\
\text { of facility equipped to address } \\
\text { the problem) }\end{array}$ & 34.7 & 13.2 & 46.4 & 34.0 & 26.4 & 38.1 \\
\hline $\begin{array}{l}\text { Higher level facility (equipped to } \\
\text { address the problem, but not } \\
\text { necessarily required) }\end{array}$ & 25.4 & 62.3 & 4.1 & 35.4 & 73.6 & 13.4 \\
\hline
\end{tabular}

Note: Percentages may not add to 100 because of don't know cases. 
Figure 4.5: Correct specific knowledge of contraceptive methods among ASHAs, according to residence

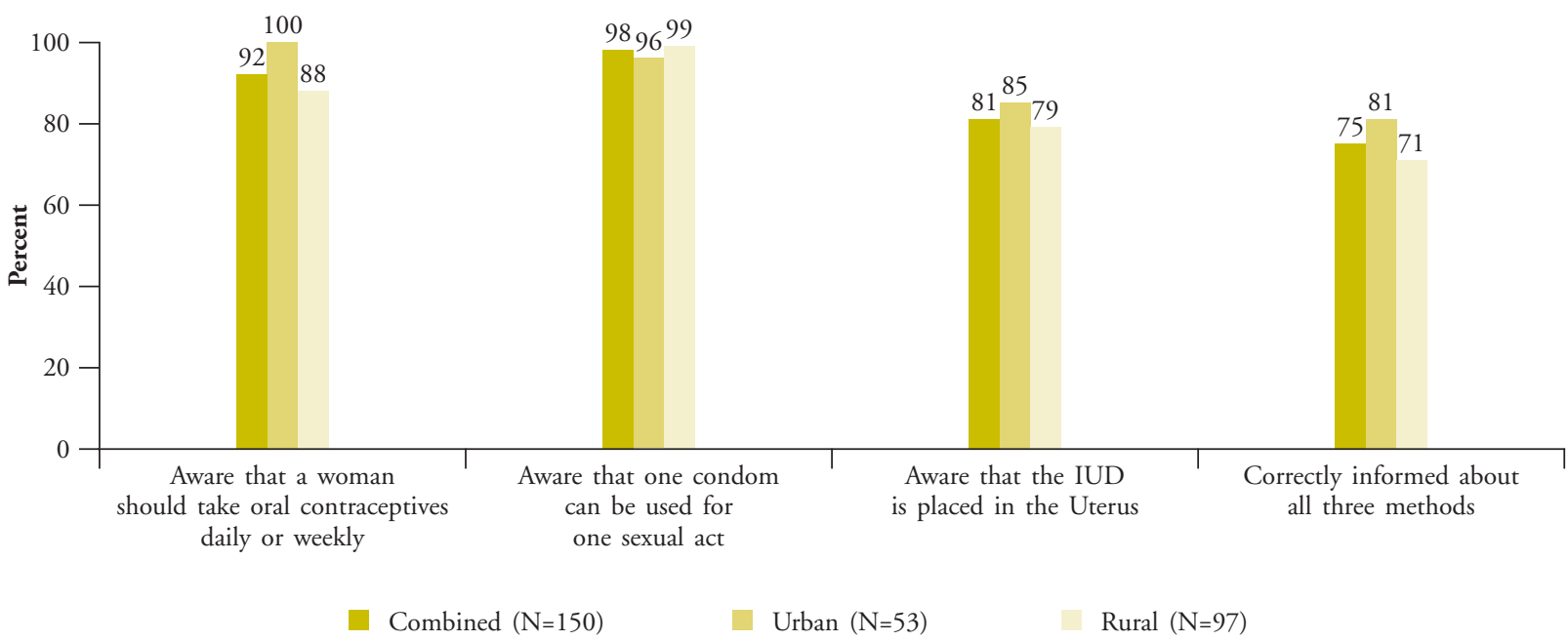

ASHAs in rural than urban areas reported so $38 \%$ versus $26 \%$ reporting that a woman experiencing antepartum bleeding must go to an First Referral Unit (FRU), for example). Some $25-35 \%$ of ASHAs reported that women experiencing these complications must go to a higher level facility, although a visit to such facilities was not required; for example, women experiencing puffiness of the face going to a community health centre or district hospital and those experiencing antepartum bleeding to a district hospital. A larger proportion of urban than rural ASHAs so reported, perhaps, because of easier access to higher level facilities in urban than rural areas $(74 \%$ versus $13 \%$ reporting that a woman experiencing antepartum bleeding must go to a district hospital, for example).

\section{Knowledge of contraceptive methods}

The study also assessed the extent of correct specific knowledge of contraceptive methods by inquiring whether the ASHAs were aware of the frequency with which oral contraceptives must be consumed (daily or weekly), the number of sex acts for which one condom can be used (one) and where the IUD is placed (uterus). Findings, presented in Figure 4.5, show high in-depth awareness of contraceptive methods among ASHAs; more than 90 percent of ASHAs knew that a woman should take oral contraceptives daily or weekly $(92 \%)$ and that one condom can be used for just one sexual act (98\%). Somewhat fewer (81\%) knew that the IUD is placed in the uterus. Three-quarters of ASHAs were correctly informed about all three topics, with more urban than rural ASHAs reporting so (81\% versus $71 \%)$. 


\section{CHAPTER 5}

\section{Services provided by ASHAs}

The study also probed about the kinds of services provided by ASHAs to women in their community in the three months preceding the interview and the number of women to whom they had given such services. Specifically, we probed about the maternal and newborn care services given by ASHAs to pregnant and recently-delivered women; contraceptive services provided to men and women, in general, and newly-married women, in particular; and services given to women to access the JSY cash benefit.

\section{Antenatal care services}

Table 5.1 summarises the antenatal care services provided by ASHAs to pregnant women in the three months preceding the interview. Almost all ASHAs
(95-96\%) reported that during the three-month period, they had assisted pregnant women to register for antenatal services, provided antenatal counseling and assisted them to access nutritious food from Anganwadi centres, with little rural-urban differences. Somewhat fewer ASHAs (85\%) reported that they had assisted pregnant women to receive three antenatal check-ups. ASHAs who had performed these tasks had served, on average, 8-10 women in the last three months; we note that these numbers correspond closely to the total number of women who had delivered in the last three months in the study villages, as assessed from the survey of women. At the same time, we note from the companion study of women who had delivered in the one year preceding the interview that even in villages and

\section{Table 5.1}

Percentage of ASHAs by antenatal care services provided to pregnant women in the three months preceding the interview, according to residence

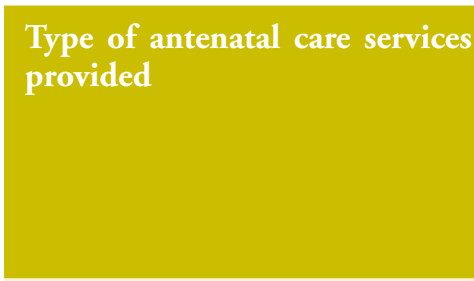

Assisted pregnant women to register for antenatal services

Assisted pregnant women to access three antenatal check-ups

Counseled pregnant women about care during pregnancy

Assisted pregnant women to access nutritious food from Anganwadi centres

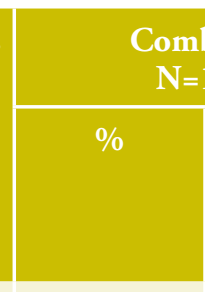

95.3

84.7

96.0

7.7

7.8

10.2

98.1

95.3

Urban
$\mathrm{N}=53$

7.6

93.8

7.4
98.1

81.1

6.7

7.8

94.8

95.9
Rural $\mathbf{N}=97$

$\% \quad$ Mean number

of women

reached 
urban wards served by ASHAs, only 30 percent of women had received the ASHA's assistance during pregnancy (Santhya et al., 2011). This inconsistency in reporting may be because women may not have taken the ASHA's contribution seriously and hence, did not report it to the survey team or because the ASHAs may have overestimated their contribution.

ASHAs who had counseled pregnant women about care during pregnancy reported that they had typically discussed the importance of three antenatal check-ups, TT injection and IFA supplements; 59-67 percent of ASHAs so reported (not shown in table). Such topics as delivery preparations and danger signs during pregnancy and delivery had been discussed by fewer ASHAs; for example, just 37 percent of ASHAs reported discussing danger signs during pregnancy.

\section{Delivery care services}

Table 5.2 presents the various delivery care services provided to pregnant women by the ASHAs.

Findings show that almost all ASHAs (97\%), regardless of rural-urban residence, reported that they had assisted pregnant women to identify a health facility for delivery. ASHAs who had offered such assistance had, on average, served eight women in the three months preceding the interview, which again corresponds to the total number of women who had delivered during this period in the study villages or urban wards, as assessed from the survey of women. ASHAs who had provided such assistance had typically recommended a primary health centre (40\%), a community health centre $(31 \%)$ or a district hospital (26\%) (not shown in table). Some four percent of ASHAs reported that they had recommended a sub-centre, although sub-centres, by

Table 5.2

Percentage of ASHAs by delivery care services provided to pregnant women in the three months preceding the interview, according to residence

\begin{tabular}{|c|c|c|c|c|c|c|}
\hline \multirow[t]{2}{*}{$\begin{array}{l}\text { Type of delivery care services } \\
\text { provided }\end{array}$} & \multicolumn{2}{|c|}{$\begin{array}{l}\text { Combined } \\
\mathbf{N}=150\end{array}$} & \multicolumn{2}{|c|}{$\begin{array}{l}\text { Urban } \\
N=53\end{array}$} & \multicolumn{2}{|c|}{$\begin{array}{l}\text { Rural } \\
\mathrm{N}=97\end{array}$} \\
\hline & $\%$ & $\begin{array}{l}\text { Mean } \\
\text { number } \\
\text { of women } \\
\text { served }\end{array}$ & $\%$ & $\begin{array}{l}\text { Mean } \\
\text { number } \\
\text { of women } \\
\text { served }\end{array}$ & $\%$ & $\begin{array}{c}\text { Mean } \\
\text { number } \\
\text { of women } \\
\text { served }\end{array}$ \\
\hline $\begin{array}{l}\text { Assisted pregnant women to } \\
\text { identify a health facility for } \\
\text { delivery }\end{array}$ & 96.7 & 8.1 & 96.2 & 8.6 & 96.9 & 7.8 \\
\hline $\begin{array}{l}\text { Arranged transport for pregnant } \\
\text { women to go to a health } \\
\text { facility for delivery }\end{array}$ & 40.0 & 3.2 & 17.0 & 2.7 & 52.6 & 3.3 \\
\hline $\begin{array}{l}\text { Used telephone helpline to call } \\
\text { transport }\end{array}$ & 10.7 & - & 11.3 & - & 10.3 & - \\
\hline $\begin{array}{l}\text { Accompanied pregnant women } \\
\text { to a health facility for } \\
\text { delivery }\end{array}$ & 70.7 & 3.7 & 67.9 & 3.5 & 72.2 & 3.8 \\
\hline $\begin{array}{l}\text { Stayed with pregnant women } \\
\text { till they were discharged } \\
\text { from the health facility after } \\
\text { delivery }\end{array}$ & 50.0 & - & 32.1 & - & 59.8 & - \\
\hline
\end{tabular}

Note: — data not available 
and large, are not among JSY-eligible health facilities. Not a single ASHA reported having recommended an accredited private hospital. The ASHA's choice of facility appears to be guided by such considerations as proximity of the facility, the behavior of the health care provider, availability of medicines and other supplies, availability of the health care provider and availability of a female health care provider.

The key factors underlying the ASHA's choice of a health facility for a woman's delivery varied by the type of facility as shown in Table 5.3. For example, among ASHAs who typically recommended a primary health centre, the close proximity of the facility was the leading consideration, with 86 percent of ASHAs citing so. Among those who had typically recommended a community health centre, while the location of the facility within close vicinity of the woman's house was a major consideration, the availability of medicines and other supplies was considered to be equally important (67\% and 56\% of ASHAs reported these reasons, respectively). Finally, ASHAs who had typically recommended a district hospital explained that they had done so for such reasons as the availability of the health care provider $(65 \%)$, the availability of medicines and other supplies $(65 \%)$, the nearness of the facility to the woman's house $(60 \%)$ and the respectful behavior of the health care provider (41\%).

Table 5.2 further shows that such tasks as escorting pregnant women to a health facility for delivery, arranging transport for them to reach the health facility, and staying with them till they are discharged from the facility after delivery were performed by fewer ASHAs. For example, just 71 percent of ASHAs reported that they had escorted pregnant women to a health facility for delivery in the three months preceding the interview; ruralurban differences were narrow. ASHAs who had done so, had served, on average, just four women in the last three months. ASHAs who had not accompanied pregnant women for delivery, frequently mentioned such reasons as not being informed by the pregnant woman's family and their own inability to do so due to household responsibilities. Lack of cooperation from staff at the health facility and the pregnant woman's decision to go to a private health facility for delivery were also cited, although, rarely (not shown in table). Further, only two-fifths of ASHAs reported making transportation arrangements for women to go to a health facility for delivery; a larger proportion of ASHAs in rural than urban areas so reported (53\% versus $17 \%)$. The average

\section{Table 5.3}

Percentage of ASHAs by reasons cited for recommending a particular health facility, according to type of health facility

\begin{tabular}{|l|c|c|c|}
\hline Reasons for recommending a health facility & $\begin{array}{c}\text { Primary } \\
\text { health centre } \\
\mathbf{N = 5 8}\end{array}$ & $\begin{array}{c}\text { Community } \\
\text { health centre } \\
\mathbf{N = 4 5}\end{array}$ & $\begin{array}{c}\text { District } \\
\text { hospital } \\
\text { N=37 }\end{array}$ \\
\hline Proximity of the health facility to the woman's house & 86.2 & 66.7 & 59.5 \\
\hline Good-natured behavior of the health care provider & 19.0 & 22.2 & 40.5 \\
\hline Availability of health care provider & 17.2 & 31.1 & 64.9 \\
\hline Availability of a female health care provider & 10.3 & 24.4 & 32.4 \\
\hline Availability of medicines and other supplies & 29.3 & 55.6 & 64.9 \\
\hline
\end{tabular}

Note: Multiple responses have been given. 
number of women who were thus assisted was just three in the last three months. Besides, just 11 percent of ASHAs reported that they had used the telephone helpline to call for the free ambulance service.

One-half of ASHAs reported that they had stayed with at least one of the pregnant women they had accompanied till her discharge from the health facility after delivery; ASHAs in rural areas were more likely than their urban counterparts to report so $(60 \%$ versus $32 \%$ ) (Table 5.2). ASHAs who had not stayed with the women till their discharge attributed it to family responsibilities (not shown in table).

\section{Postpartum and newborn care services}

Table 5.4 presents the postpartum and newborn care services given by ASHAs to women who had delivered recently. Over 90 percent of ASHAs reported that they had visited recently-delivered women within a week of delivery in the three months preceding the interview; rural-urban differences were modest. On average, an ASHA had made postpartum visits to some five women in the last three months. Further, half as many ASHAs had visited recently-delivered women within two days of delivery (47\%); ASHAs in rural areas were somewhat more likely than their urban counterparts to have done so (51\% versus 42\%). ASHAs who had made postpartum visits said that they had typically discussed how to take care of the newborn (91\%), breastfeeding (80\%) and care of the mother (78\%) (not shown in table). They had rarely discussed such topics as the importance of postpartum checkups $(29 \%)$, danger signs during the postpartum period (12\%), danger signs among newborns (23\%) and postpartum contraception (1\%) in spite of the widespread awareness about these topics among ASHAs.

Further, over 90 percent of ASHAs reported that they had assisted recently-delivered women to get their infant immunised; rural-urban differences were modest. ASHAs, on average, had assisted some 11 women in the three months preceding the interview.

\section{Table 5.4}

Percentage of ASHAs by postpartum and newborn care services provided to recently-delivered women in the three months preceding the interview, according to residence

\begin{tabular}{|c|c|c|c|c|c|c|}
\hline \multirow{2}{*}{$\begin{array}{l}\text { Type of postpartum and } \\
\text { newborn care services } \\
\text { provided }\end{array}$} & \multicolumn{2}{|c|}{$\begin{array}{c}\text { Combined } \\
\mathrm{N}=150\end{array}$} & \multicolumn{2}{|c|}{$\begin{array}{l}\text { Urban } \\
N=53\end{array}$} & \multicolumn{2}{|c|}{$\begin{array}{l}\text { Rural } \\
N=97\end{array}$} \\
\hline & $\%$ & $\begin{array}{l}\text { Mean } \\
\text { number } \\
\text { of women } \\
\text { reached }\end{array}$ & $\%$ & $\begin{array}{l}\text { Mean } \\
\text { number } \\
\text { of women } \\
\text { reached }\end{array}$ & $\%$ & $\begin{array}{l}\text { Mean } \\
\text { number } \\
\text { of women } \\
\text { reached }\end{array}$ \\
\hline $\begin{array}{l}\text { Visited recently-delivered } \\
\text { women within a week of } \\
\text { delivery }\end{array}$ & 92.7 & 5.4 & 96.2 & 5.0 & 90.7 & 5.6 \\
\hline $\begin{array}{l}\text { Visited recently-delivered } \\
\text { women within two days of } \\
\text { delivery }\end{array}$ & 47.4 & - & 41.5 & - & 50.5 & - \\
\hline $\begin{array}{l}\text { Assisted recently-delivered } \\
\text { women to get their infant } \\
\text { immunised }\end{array}$ & 92.7 & 10.6 & 88.7 & 14.5 & 94.8 & 8.8 \\
\hline
\end{tabular}

Note: — data not available. 


\section{Contraceptive counseling and supplies}

Questions were also included to assess the extent to which the ASHAs were engaged in providing family planning counseling to newly-married women and distributing such methods as oral contraceptives and condoms to women and men in the community. Findings are presented in Figure 5.1 and suggest that the interactions of ASHAs with married young women are limited. Just one-third of ASHAs reported that they had given information on family planning to newly-married women in the three months preceding the interview, with little ruralurban difference. ASHAs who had done so, on average, had counseled three women in the last three months (not shown in table). However, threequarters of ASHAs reported that they had supplied oral contraceptives; more ASHAs in urban than rural areas so reported (83\% versus $68 \%$ ). One-quarter of ASHAs reported that they had supplied condoms; ASHAs in rural areas were more likely than their urban counterparts to report so (29\% versus $17 \%)$.

\section{Services given to women to access the JSY cash benefit}

Under the JSY, the ASHA is also expected to assist pregnant and recently-delivered women to access the stipulated cash benefit. The study contained a number of questions to assess the extent to which ASHAs had performed this task as also any difficulties that they may have faced in doing so. Findings are presented in Table 5.5. Over 90 percent of ASHAs reported that they had assisted pregnant and recently-delivered women to access their JSY entitlement, with little rural-urban difference. ASHAs who had done so had, on average, served three women in the three months preceding the interview. A quarter of ASHAs reported that the women they had assisted had waited for more than a week to get their cash entitlement and almost one-tenth said that the women they had assisted had waited for more than a month; rural ASHAs were more likely than their urban counterparts to report such delays. Some seven percent of ASHAs reported that, in addition to

Figure 5.1: Contraceptive counseling and supplies provided by ASHAs to women and men in the three months preceding the interview, according to residence

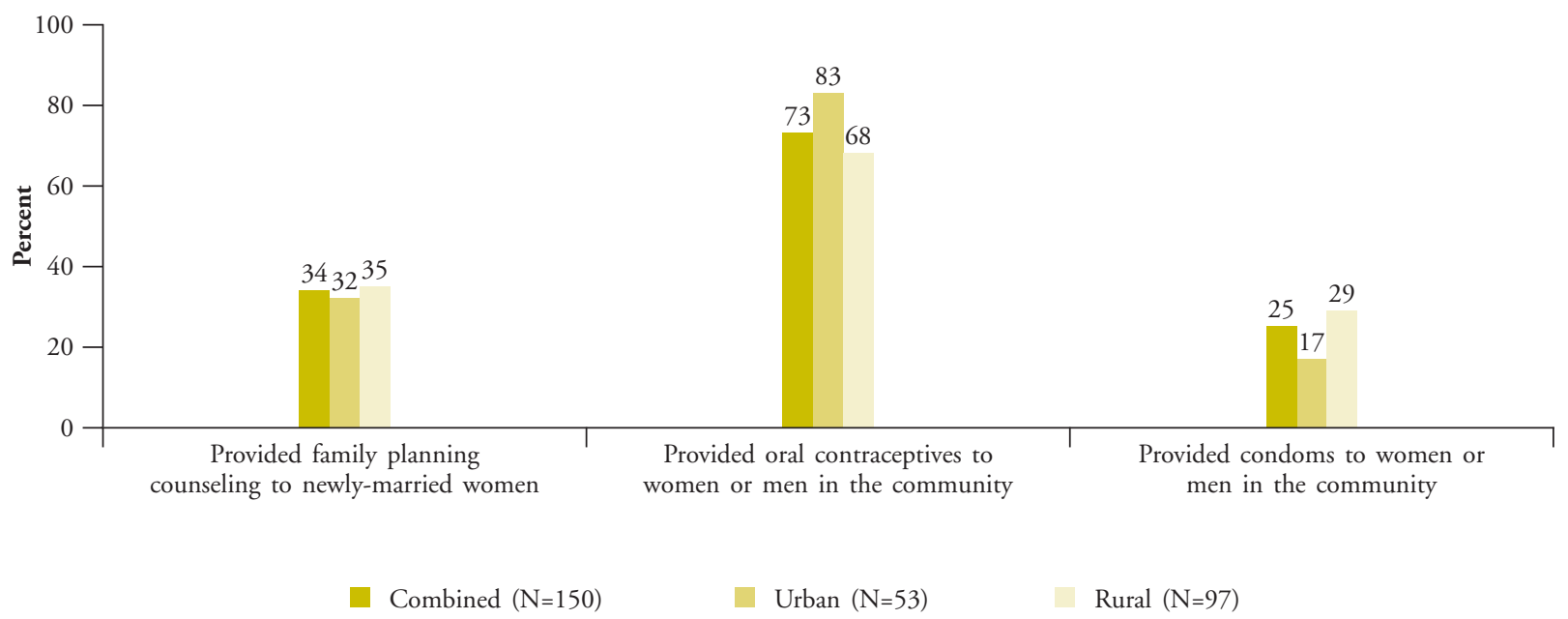




\section{Table 5.5}

Percentage of ASHAs reporting experiences of assisting women to obtain the JSY cash benefit in the three months preceding the interview, according to residence

\begin{tabular}{|c|c|c|c|}
\hline $\begin{array}{l}\text { Experience of assisting women to obtain the JSY } \\
\text { cash benefit }\end{array}$ & $\begin{array}{l}\text { Combined } \\
\mathrm{N}=150\end{array}$ & $\begin{array}{l}\text { Urban } \\
\mathrm{N}=53\end{array}$ & $\begin{array}{l}\text { Rural } \\
\mathbf{N}=97\end{array}$ \\
\hline $\begin{array}{l}\text { Assisted pregnant/recently delivered women to obtain } \\
\text { JSY money }\end{array}$ & 93.3 & 90.6 & 94.8 \\
\hline \multicolumn{4}{|l|}{ Among those provided assistance } \\
\hline Mean number of women assisted & 2.8 & 2.6 & 2.9 \\
\hline $\begin{array}{l}\text { Women who waited for more than one week to get JSY } \\
\text { money }\end{array}$ & 25.0 & 18.8 & 28.3 \\
\hline $\begin{array}{l}\text { Women who waited for more than one month to get } \\
\text { JSY money }\end{array}$ & 9.3 & 4.2 & 12.0 \\
\hline $\begin{array}{l}\text { ASHAs who received money from the last woman who } \\
\text { she had assisted to obtain JSY money }\end{array}$ & 7.1 & 10.4 & 5.4 \\
\hline
\end{tabular}

the incentive received from the health department, they had received some money from the last woman thus assisted, urban ASHAs being more likely than rural ASHAs to report so.

\section{Incentives received by ASHAs}

ASHAs who reported that they had assisted women to procure JSY benefits were asked whether they had received any money from the health department, the amount of money they had received and, if so, the ease/difficulty with which they had received the money. Findings, presented in Table 5.6, indicate that almost nine out of 10 ASHAs, regardless of rural-urban residence, reported that they had received some money from the health department for assisting women to access the JSY cash benefit. Of those who had received some money, threequarters reported that they had received the money without any delay; urban ASHAs were more likely than the rural to report so $(85 \%$ versus $70 \%)$. For the last woman assisted, rural ASHAs had received Rs. 424 while urban ASHAs had received Rs. 138

\section{Table 5.6}

Percentage of ASHAs who received the JSY cash incentive, according to residence

\section{Receipt of cash incentive \\ Received money from the health department \\ Among ASHAs who received incentive money from the bealth department}

Combined
$\mathbf{N}=150$

88.0

75.0

NA

18.9

Urban
$\mathrm{N}=53$

86.8
Rural

$\mathrm{N}=97$

88.7

Received money without any delay

84.8

69.8

Average amount received for the last woman assisted (in Rs)

Experienced some difficulty in getting money

138

424

28.3

14.0

Note: (NA) Not Applicable. 
from the health department. We note that the average amount received was much less than the amount stipulated in the JSY guidelines; this may be because the stipulated amount is apportioned for different activities and the ASHAs who participated in the study may not have performed the full range of activities. One in five ASHAs reported that they had experienced some difficulty in getting the money, with urban ASHAs twice as likely as rural ASHAs to report so (28\% versus $14 \%)$; the difficulty experienced was primarily related to delays in receiving payment.

\section{Difficulties experienced by ASHAs in carrying out JSY-related tasks}

ASHAs were asked about the difficulties that they had experienced in carrying out JSY-related tasks. While one-half of ASHAs reported that they had not experienced any difficulty in performing the tasks assigned to them, others cited a number of constraints (Table 5.7). The major constraint experienced by ASHAs, regardless of rural-urban residence, was mistreatment, including disrespect shown by women and their family, reported by 24 percent of ASHAs. Other constraints included difficulty in procuring good quality services for women whom they had escorted to the health facility for delivery (9\%), delayed payments (9\%) and inconvenience in staying in the health facility (5\%). ASHAs in urban areas were more likely than their rural counterparts to report difficulty in getting good quality services for the women they had escorted (23\% versus $2 \%)$ and delayed payment (15\% versus 5\%), but less likely to report inconvenience in staying in the health facility (none versus $7 \%)$.

\section{Perceptions of ASHAs about the JSY}

In order to assess the perceptions of ASHAs about the JSY, they were asked whether they thought that the JSY could improve the utilisation of maternal and child health services and reasons if they thought otherwise, whether there had been any shortcomings in the implementation of the JSY and, if so, their suggestions for improving the implementation of the scheme. Almost all ASHAs, regardless of ruralurban residence, believed that the JSY could improve the utilisation of maternal and child health services (Table 5.8). About one-quarter of ASHAs said that there were shortcomings in the implementation of

Table 5.7

Percentage of ASHAs by difficulties experienced in carrying out JSY-related tasks, according to residence

\begin{tabular}{|l|c|c|c|}
\hline Difficulties cited & $\begin{array}{c}\text { Combined } \\
\text { N=150 }\end{array}$ & $\begin{array}{c}\text { Urban } \\
\mathbf{N}=53\end{array}$ & $\begin{array}{c}\text { Rural } \\
\text { N=97 }\end{array}$ \\
\hline Mistreatment of ASHAs by women and their family & 24.0 & 22.6 & 24.7 \\
\hline $\begin{array}{l}\text { Difficulty in getting good quality services for women } \\
\text { escorted to the health facility }\end{array}$ & 9.3 & 22.6 & 2.1 \\
\hline Delayed payment & 8.7 & 15.1 & 5.2 \\
\hline Inconvenience in staying in the health facility & 4.7 & 0.0 & 7.2 \\
\hline Mistreatment by ANMs & 1.3 & 1.9 & 1.0 \\
\hline Other & 4.7 & 5.7 & 4.1 \\
\hline Did not experience any difficulty & 51.3 & 43.4 & 55.7 \\
\hline
\end{tabular}

Note: The percentages add up to more than 100 due to multiple responses. 


\section{Table 5.8}

Percentage of ASHAs reporting perceptions about the JSY, according to residence

\begin{tabular}{|l|c|c|c|}
\hline ASHAs who reported that & $\begin{array}{c}\text { Combined } \\
\mathbf{N}=150\end{array}$ & $\begin{array}{c}\text { Urban } \\
\mathbf{N}=53\end{array}$ & $\begin{array}{c}\text { Rural } \\
\mathbf{N}=97\end{array}$ \\
\hline $\begin{array}{l}\text { The JSY can improve utilisation of maternal and } \\
\text { health services }\end{array}$ & 98.7 & 96.2 & 100.0 \\
\hline $\begin{array}{l}\text { There are shortcomings in the current implementation } \\
\text { of the JSY }\end{array}$ & 23.3 & 22.6 & 23.7 \\
\hline
\end{tabular}

\section{Table 5.9}

Percentage of ASHAs by suggestions offered for improving JSY implementation, according to residence

\begin{tabular}{|c|c|c|c|}
\hline Suggestions for improving JSY implementation & $\begin{array}{l}\text { Combined } \\
\mathrm{N}=150\end{array}$ & $\begin{array}{l}\text { Urban } \\
\mathrm{N}=53\end{array}$ & $\begin{array}{l}\text { Rural } \\
\mathbf{N}=97\end{array}$ \\
\hline Improve the quality of care in health facilities & 35.3 & 41.5 & 32.0 \\
\hline $\begin{array}{l}\text { Improve the disbursement of cash benefits to ASHAs } \\
\text { and increase the amount }\end{array}$ & 26.7 & 32.1 & 23.7 \\
\hline $\begin{array}{l}\text { Improve the disbursement of cash benefits to women } \\
\text { and increase the amount }\end{array}$ & 11.3 & 9.4 & 12.4 \\
\hline Improve transportation facilities & 4.0 & 0.0 & 6.2 \\
\hline Provide further training to ASHAs & 4.0 & 5.7 & 3.1 \\
\hline $\begin{array}{l}\text { Increase the availability of medicines and other supplies } \\
\text { in health facilities }\end{array}$ & 2.0 & 3.8 & 1.0 \\
\hline Raise awareness about the JSY at the community level & 1.3 & 0.0 & 2.1 \\
\hline
\end{tabular}

the JSY. These included concerns about delayed payments and poor quality of care in the health facility.

ASHAs who participated in the study made a number of suggestions for improving the implementation of the JSY scheme. Their suggestions are summarised in Table 5.9. A major suggestionput forward by one-third of ASHAs — was to improve the quality of care in health facilities; more ASHAs in urban than rural areas so recommended (42\% versus 32\%). A quarter of ASHAs suggested that the disbursement of their cash incentives should be improved and the incentive amount should be increased; again, more ASHAs in urban than rural areas so reported (32\% versus 24\%). One-tenth of ASHAs, regardless of rural-urban residence, made a similar suggestion about the disbursement and enhancement of cash incentives to beneficiary women. Small minorities of ASHAs (1\% to $4 \%$ ) also recommended improvements in transportation facilities, and in the availability of medicines and other supplies in health facilities, further training of ASHAs, and raising community awareness about the JSY. 


\section{CHAPTER 6}

\section{Summary and recommendations}

The study has brought forth several positive findings as well as areas that require future attention for improving the ASHA programme in Rajasthan.

\section{Summary}

Awareness of the JSY among ASHAs varies by theme and is far from comprehensive

Awareness of the JSY programme among ASHAs varied by theme and was far from comprehensive. The vast majority of ASHAs were aware of most of the eligibility conditions for availing of JSY benefits, including the fact that women could access JSY benefits regardless of their age, parity and household economic status, as well as the type of government health facility in which they could deliver to acquire these benefits. However, their awareness of the monetary and non-monetary support to which women are entitled under the JSY was somewhat limited. For example, only 71 percent of ASHAs knew that a woman in rural areas is entitled to Rs. 1,400 and that a woman in urban areas is entitled to Rs. 1,000 if she delivers in a government or accredited private facility. Findings, moreover, indicate considerable confusion among ASHAs with regard to their awareness of their own entitlements for assisting women to access JSY benefits. Likewise, findings present a mixed picture about their awareness of their responsibilities under the JSY. Tasks such as assisting pregnant women in registering for antenatal check-ups and seeking three antenatal check-ups, counseling them about institutional delivery, assisting them in identifying a health facility for delivery, escorting them to a health facility for delivery, making postpartum visits to them within seven days of delivery and arranging immunisation of their newborn were almost universally known. In contrast, such tasks as counseling recently-delivered women about family planning were rarely known to be among the responsibilities of the ASHA.

\section{While most ASHAs have been trained} in imparting information on sexual and reproductive matters, supportive supervision remains limited

Almost all ASHAs had received training in imparting information pertaining to contraception, care during pregnancy, delivery and the postpartum period, and newborn care. However, the extent of supervision that they received was far from satisfactory. For example, just two-fifths of ASHAs reported that the ANM had held weekly or fortnightly meetings with them in the one month preceding the survey.

\section{The credibility of ASHAs with women and their family remains low}

Findings show that while most ASHAs were confident about performing the tasks assigned to them, many believed that their credibility among women in their community was limited. Only one-quarter of ASHAs felt that women in their community took their advice seriously. 


\section{Awareness of maternal and newborn care practices among ASHAs is mixed}

ASHAs displayed in-depth awareness of best maternal and newborn care practices. For example, awareness of the number of antenatal check-ups, the required number of doses of TT injections and the number of days that IFA supplementation should be taken was almost universal. However, awareness of the appropriate timing of the first, second and third antenatal check-ups was somewhat limited. With regard to delivery care, the majority of ASHAs were aware of some of the essential birth preparations. Nine out of ten ASHAs knew that a woman should have a postpartum check-up even if she is feeling fine; however, fewer knew that a woman should have her first postpartum check-up within a few hours or, at best, within two days of delivery.

Findings show that the vast majority of ASHAs were aware of the best practices related to immediate care of the newborn. Awareness of appropriate infant feeding practices, likewise, was high. Similarly, awareness of the immunisation schedule was high.

The majority of ASHAs were aware of the complications that can occur during the antenatal period and those among newborns. However, fewer were aware of complications during labour and delivery and the postpartum period. Findings, moreover, indicate limited awareness of appropriate health facilities for treating pregnancy-related complications. For example, just one-third of ASHAs knew that a pregnant woman who experiences antepartum bleeding must go to a community health centre which is the recommended lowest level facility.

Finally, in-depth awareness of contraceptive methods was high among ASHAs; for example, over 90 percent of ASHAs knew that a woman should take oral contraceptives daily or weekly and that one condom can be used for just one sexual act.

\section{Services provided by the ASHA remain skewed}

Almost all ASHAs had counseled pregnant women about antenatal care; assisted pregnant women in registering for antenatal services, accessing nutritious food from Anganwadi centres and identifying a health facility for delivery; visited recently-delivered women within a week of delivery and assisted women in getting their baby immunised. However, fewer had assisted pregnant women in receiving three antenatal check-ups, escorted them to a health facility for delivery, arranged transport for them to reach a health facility for delivery and stayed with them till they were discharged after delivery.

Findings also indicate that the interactions of ASHAs with married young women appear to be limited; just one-third of ASHAs reported giving information on family planning to newly-married women in the three months preceding the interview.

The information imparted by ASHAs to women in the community was also skewed. ASHAs who had counseled pregnant women about care during pregnancy had typically discussed the importance of three antenatal check-ups, TT injections, and IFA supplements. Such topics as delivery preparations, and the danger signs experienced during the antenatal period, delivery and the postpartum period, as well as those among newborns had been discussed by fewer ASHAs. Likewise, ASHAs who had made postpartum visits had typically discussed how to take care of the newborn and the mother, and breastfeeding, while such topics as the importance of postpartum checkups, danger signs during the postpartum period, danger signs among newborns and postpartum contraception had rarely been discussed. 
On average, ASHAs assist one woman to avail of JSY benefits in a month

Over 90 percent of ASHAs reported that they had assisted pregnant and recently-delivered women to obtain JSY benefits, with little rural-urban difference. On average, they had assisted one woman in a month.

\section{Most ASHAs received incentives for assisting} women to access JSY benefits; however, sizeable numbers experienced delays in payment

Almost nine out of 10 ASHAs had received some money from the health department for assisting women to access JSY benefits. For the last woman whom they had assisted, ASHAs in rural and urban areas, had received, on average, Rs. 424 and Rs. 138, respectively. One in five ASHAs had experienced some difficulty in obtaining the money, primarily related to delays in receiving payments.

\section{Recommendations}

The findings of the study suggest a number of priority areas for action.

\section{Train ASHAs more comprehensively about their rights and responsibilities under the NRHM}

Findings highlight that several of the tasks articulated under the JSY are not recognised by ASHAs to be among their responsibilities. For example, staying with women till they are discharged from the health facility after delivery and counseling women about breastfeeding and postpartum contraception were not widely known as the responsibilities of the ASHA. Moreover, there exists considerable confusion about the ASHA's entitlements. These findings emphasise the need for efforts to better inform ASHAs about their entitlements and responsibilities under the NRHM.
Raise awareness of the lesser known best practices related to maternal and newborn care among ASHAs

ASHAs in our study displayed high levels of awareness of most best practices related to maternal and newborn care; however, findings that their awareness of the appropriate timing of antenatal and postpartum check-ups is rather limited call for further efforts to raise their awareness of maternal and newborn care practices. These efforts must pay special attention to increasing their awareness of the complications that a woman may experience during labour and delivery, and the postpartum period, and the appropriate health facilities for treating pregnancy-related complications.

\section{Emphasise the ASHA's engagement in promoting postpartum care}

Findings that the ASHA's engagement is largely limited to promoting antenatal and delivery care highlight the need to emphasise her role in promoting postpartum care, given that most maternal deaths take place during the postpartum period.

\section{Make special efforts to increase the credibility of ASHAs in the community}

Findings that most ASHAs perceive that women in their community rarely take their advice seriously call for efforts to increase their social skills, including interpersonal communication and self-esteem on the one hand, and to promote ASHAs as frontline health workers in the community, on the other. Mechanisms to provide supportive supervision to ASHAs by ANMs and medical officers need to be strengthened. At the same time, ANMs and medical officers must, in their contacts with women and their family members, communicate the important role played by ASHAs vis-a-vis the health of their community, and convey the health system's confidence in their abilities. 


\section{APPENDIX 1 \\ Janani Suraksha Yojana (JSY): Features and Frequently Asked Questions and Answers}

\section{Accessed on 20 November, 2001 at http://www.mohfw.nic.in/WriteReadData/1892s/file28-99526408.pdf}

1. Janani Suraksha Yojana (JSY) is a safe motherhood intervention under the National Rural Health Mission (NRHM) being implemented with the objective of reducing maternal and neo-natal mortality by promoting institutional delivery among the poor pregnant women. The Yojana, launched on 12th April 2005, by the Hon'ble Prime Minister, is being implemented in all states and UTs with special focus on low performing states.

2. JSY is a $100 \%$ centrally sponsored scheme and it integrates cash assistance with delivery and post-delivery care. The success of the scheme would be determined by the increase in institutional delivery among the poor families.

3. The Yojana has identified ASHA, the accredited social health activist as an effective link between the Government and the poor pregnant women in 10 low performing states, namely the 8 EAG states and Assam and J\&K and the remaining NE States. In other eligible states and UTs, wherever, AWW and TBAs or ASHA like activist has been engaged in this purpose, she can be associated with this Yojana for providing the services.

3.1 Role of ASHA or other link health worker associated with JSY would be to:

- Identify pregnant woman as a beneficiary of the scheme and report or facilitate registration for ANC,

- Assist the pregnant woman to obtain necessary certifications wherever necessary,

- Provide and/or help the women in receiving at least three ANC checkups including TT injections, IFA tablets,

- Identify a functional Government health centre or an accredited private health institution for referral and delivery,

- Counsel for institutional delivery,

- Escort the beneficiary women to the pre-determined health center and stay with her till the woman is discharged,

- Arrange to immunize the newborn till the age of 14 weeks,

- Inform about the birth or death of the child or mother to the ANM/MO,

- Post natal visit within 7 days of delivery to track mother's health after delivery and facilitate in obtaining care, wherever necessary,

- Counsel for initiation of breastfeeding to the newborn within one-hour of delivery and its continuance till 3-6 months and promote family planning.

Note: Work of the ASHA or any link worker associated with Yojana would be assessed based on the number of pregnant women she has been able to motivate to deliver in a health institution and the number of women she has escorted to the health institutions. 
4. Important Features of JSY:

4.1 The scheme focuses on the poor pregnant woman with special dispensation for states having low institutional delivery rates namely the states of Uttar Pradesh, Uttaranchal, Bihar, Jharkhand, Madhya Pradesh, Chhattisgarh, Assam, Rajasthan, Orissa and Jammu and Kashmir. While these states have been named as Low Performing States (LPS), the remaining states have been named as High performing States (HPS).

4.2 Tracking Each Pregnancy: Each beneficiary registered under this Yojana should have a JSY card along with a MCH card. ASHA/AWW/any other identified link worker under the overall supervision of the ANM and the MO, PHC should mandatorily prepare a micro-birth plan. Please see Annexure-I. This will effectively help in monitoring Antenatal Check-up, and the post delivery care.

\subsection{Eligibility for Cash Assistance:}

LPS States All pregnant women delivering in Government health centres like Sub-centre, PHC/CHC FRU/general wards of District and state Hospitals or accredited private institutions

HPS States BPL pregnant women, aged 19 years and above

LPS \& HPS All SC and ST women delivering in a government health centre like Sub-centre, PHC/ CHC/FRU/general ward of District and state Hospitals or accredited private institutions

Note: BPL Certification-This is required in all HPS states. However, where BPL cards have not yet been issued or have not been updated, States/UTs would formulate a simple criterion for certification of poor and needy status of the expectant mother's family by empowering the gram pradhan or ward member.

4.4 Scale of Cash Assistance for Institutional Delivery:

\begin{tabular}{|l|c|c|c|c|c|c|}
\hline \multirow{2}{*}{ Category } & \multicolumn{2}{|c|}{ Rural Area } & Total & \multicolumn{2}{|c|}{ Urban Area } & Total \\
\cline { 2 - 8 } & $\begin{array}{l}\text { Mother's } \\
\text { Package }\end{array}$ & $\begin{array}{c}\text { ASHA's } \\
\text { Package }\end{array}$ & Rs. & $\begin{array}{c}\text { Mother's } \\
\text { Package }\end{array}$ & $\begin{array}{c}\text { ASHA's } \\
\text { Package }\end{array}$ & Rs. \\
\hline LPS & 1400 & 600 & 2000 & 1000 & 200 & 1200 \\
\hline HPS & 700 & & 700 & 600 & & 600 \\
\hline
\end{tabular}

Note 1: Importantly, such woman in both LPS and HPS states, choosing to deliver in an accredited private health institution will have to produce a proper BPL or a SC/ST certificate in order to access JSY benefits. In addition she should carry a referral slip from the ASHA/ANM/MO and the MCH—Janani Suraksha Yojana (JSY) card.

Note 2: ANM/ASHA/MO should make it clear to the beneficiary that Government is not responsible for the cost of her delivery. She has to bear cost, while choosing to go to an accredited private institution for delivery. She only gets her entitled cash.

4.5 While mother will receive her entitled cash, the scheme does not provide for ASHA package for such pregnant women choosing to deliver in an accredited private institution. 
4.6 Limitations of Cash Assistance for Institutional Delivery:

In LPS States All births, delivered in a health centre-Government or Accredited Private health institutions. Refer to para (b).

In HPS States Upto 2 live births.

4.7 Disbursement of Cash Assistance: As the cash assistance to the mother is mainly to meet the cost of delivery, it should be disbursed effectively at the institution itself.

4.7.1 For pregnant women going to a public health institution for delivery, entire cash entitlement should be disbursed to her in one go, at the health institution. Considering that some women would access accrediting private institution for antenatal care, they would require some financial support to get atleast 3 ANCs including the TT injections. In such cases, atleast three-fourth (3/4) of the cash assistance under JSY should be paid to the beneficiary in one go, importantly, at the time of delivery.

\subsubsection{To Beneficiary:}

a. The mother and the ASHA (wherever applicable) should get their entitled money at the heath centre immediately on arrival and registration for delivery.

b. Generally the ANM/ASHA should carry out the entire disbursement process. However, till ASHA joins, AWW or any identified link worker, under the guidance of the ANM may also do the disbursement.

4.7.3 At accredited private institution: Disbursement of cash to the mother should be done through the ANM/ASHA/Link worker channel and the money available under JSY should be paid to the beneficiary only and not to any other person or relative. Also refer to para (e).

Should ensure that:

- Such accredited private institution would also be responsible for any postnatal complication arising out of the cases handled by them.

- They should not deny their services to any referred targeted expectant mother.

Note: Every month, accredited private health centers would prepare a statement of JSY — delivery/ANClobstetric complication cases handled by them and send it to the Medical officer, along with the referral slips for sample verification by the concerned ANM/ASHA.

4.7.4 In the District/Women's Hospital/State Hospital etc :

- State/District should allocate sufficient amount of money (based on the load of deliveries in these institutions) for each of these institution. This money should be kept in a separate account under the supervision of the Rogi Kalyan Samity.

- The residency of the beneficiary would determine entitlement of cash benefit in such institutions, to be verified based on the referral slip from the ANM, carried by the beneficiary. 
Format of Referral Slip: State should prepare a format of the referral slip, which should mainly indicate, identification details of the beneficiary, JSY registration number in the register of the ANM, reason for referral (including medical complications), name of ASHA, amount already disbursed, amount due, including referral transport money (if applicable), amount due to ASHA and to be paid, signature of MO/ANM.

- It is therefore, essential that all targeted expectant mother should carry a referral slip from the ANM/MO where she generally resides. This will, infact, help all such pregnant woman who go to her mother's place for delivery.

- Disbursement of money to expectant mother going to her mother's place for delivery should be done at the place she delivers. The entitlement of cash should be determined by her referral slip carried by her and her usual place of residence.

- A voucher scheme may be introduced in such a way that along with admission slip for delivery, a voucher amounting to mother's package plus the transport assistance money is given to the expectant mother and that she should be able to encash the same at the Hospital's cash counter, at the time of discharge.

4.8 Flow of Fund:

i. State/District authorities would advance Rs. 5,000/- and Rs. Rs. 10,000/- to each ANM in HPS/LPS States respectively as a recoupable impressed money from the JSY fund.

ii. This money could be kept in the joint account of ANM and Gram Pradhan, as in case of untied fund placed with sub-centers so that the ANM could 'roll' the entire amount by advancing Rs. 1,500 to Rs. 2,500/- to ASHA/AWW per delivery and later she could recoup it from the PHC or CHC, where JSY fund is parked by the authorities.

Expenditure Monitoring: ASHA/AWW should provide an expenditure statement of money advanced to her in previous month to the ANM in the monthly meeting held by ANM.

iii. There should be a clear authority for ANM to withdraw cash from this account for advancing it to the ASHA or AWW/any other health link worker, needed for ready use towards disbursement to the pregnant and also for arranging the referral transport for escorting the pregnant women to the institution.

Note: Where an elected body of the Panchayati Raj Institution (PRIs) exists, the State Governments/Health society may keep the money in a joint account of the Gram Pradhan and the ANM (like that of the untied fund). The process of recoupment of fund should be so simple to be able to disburse the cash to the pregnant women in time. 
Implementing the Janani Suraksha Yojana: Perspectives and experiences of Accredited Social Health Activists in Rajasthan

4.9 ASHA Package: This package, as of now, is available in all LPS, NE States and in the tribal districts of all states and UTs. In rural areas it includes the following three components:

- Cash assistance for Referral transport to go to the nearest health centre for delivery. The state will determine the amount of assistance (should not less than Rs. 250/- per delivery) depending on the topography and the infrastructure available in their state. It would, however, be the duty of the ASHA and the ANM to organize or facilitate in organizing referral the transport, in conjunction with gram pradhan, Gram Sabha etc.

Note: This assistance is over and above the Mother's package.

- Cash incentive to ASHA: This should not be less than Rs. 200/- per delivery in lieu of her work relating to facilitating institutional delivery. Generally, ASHA should get this money after her postnatal visit to the beneficiary and that the child has been immunized for BCG.

- Transactional cost (Balance out of Rs. 600/-) is to be paid to ASHA in lieu of her stay with the pregnant woman in the health centre for delivery to meet her cost of boarding and lodging etc.. Therefore, this payment should be made at the hospital/heath institution itself.

Note 1: In Urban areas, ASHA package consists of only the incentive for ASHA, for providing the services, as at para 3.1 Note 2: In case ASHA fails to organize transport for the pregnant woman to go to the health institution, transport assistance money available within the ASHA's package should be paid to the pregnant woman at the institution, immediately on arrival and registration for delivery.

Note 3: In case ASHA is yet to join, transport assistance money may be kept with the institution and a voucher scheme may be introduced for disbursement.

4.10 Payment to ASHA: ASHA should get her-

- First payment for the transactional cost at the health centre on reaching the institution along with the expectant mother.

- The second payment should be paid after she has made postnatal visit and the child has been immunized for BCG.

All payments to ASHA would be done by the ANM only. In this case too, a voucher scheme be introduced in such a manner that for every pregnant woman she registers under JSY, ANM would give two vouchers to ASHA, which she would be able to encash on certification by ANM.

Important: It must be ensured that ASHA gets her second payment within 7 days of the delivery, as that would be essential to keep her sustained in the system.

4.11 Special Dispensation for LPS states:

- Age restriction removed.

- Restricting benefits of JSY up to 2 births removed. In other words, the benefits of the scheme are extended to all pregnant women in LPS states irrespective of birth orders. 
- No need for any marriage or BPL certification provided woman delivers in Government or accredited private health institution.

Important: The state/UTs would be responsible for instituting an appropriate monitoring mechanism and ensure that a proper accounting procedure is put in place for all transactions.

4.12 Subsidizing cost of Caesarean Section or management of Obstetric complications: Generally PHCs/FRUs/CHCs etc. would provide emergency obstetric services free of cost. Where Government specialists are not available in the Govt's health institution to manage complications or for Caesarean Section, assistance up to Rs. 1,500/- per delivery could be utilized by the health institution for hiring services of specialists from the private sector. If a specialist is not available or that the list of empanelled specialist is very few, specialist doctors working in the other Government set-ups may even be empanelled, provided his/her services are spare and he/she is willing. In such a situation, the cash subsidy can be utilized to pay honorarium or for meeting transport cost to bring the specialist to the health centre. It may however be remembered that a panel of such doctors from private or Government institutions need to be prepared beforehand in all such health institutions where such facility would be provided and the pregnant women are informed of this facility, at time of micro-birth planning.

Important: State Governments would ensure that this assistance is not misutilized and would exercise adequate control and monitor expenditure under this component.

4.13 Assistance for Home Delivery: In LPS and HPS States, BPL pregnant women, aged 19 years and above, preferring to deliver at home is entitled to cash assistance of Rs. 500/- per delivery. Such cash assistance would be available only upto 2 live births and the disbursement would be done at the time of delivery or around 7 days before the delivery by ANM/ASHA/any other link worker. The rationale is that beneficiary would be able to use the cash assistance for her care during delivery or to meet incidental expenses of delivery. It should be the responsibility of ANM/ASHA, MO PHC to ensure disbursement. It is very important that the cash is disbursed in time. Importantly, such woman choosing to deliver at home should have a BPL certificate to access JSY benefits.

5. Compensation Money: If the mother or her husband, of their own will, undergoes sterilization, immediately after the delivery of the child, compensation money available under the existing Family welfare scheme should also be disbursed to the mother at the hospital itself.

6. JSY Benefits in Accredited Private Health Institution: In order to increase choice of delivery care institutions, at least two willing private institutions per block should be accredited to provide delivery services. State and the district authorities should draw up a list of criterion/protocols for such accreditation. (Please see a model criterion at Annexure-2) Such beneficiaries delivering in these institutions would get the cash benefits admissible under the JSY. 
7. Equip Sub-centers for Normal delivery: For women living in tribal and hilly districts, it becomes difficult to access $\mathrm{PHC} / \mathrm{CHCs}$ for maternal care or delivery. A well-equipped sub-center is a better option for normal delivery. Deliveries conducted in sub-centers, which are accredited by the state/district authorities will be considered as institutional delivery and therefore, women delivering in these centers would be eligible for all cash assistance under JSY.

Important: All States and UTs to undertake a process of accreditation of all such sub-centre located in Govt. buildings and having proper facility of light, electricity, water, and other medical requirements of basic obstetric services including drugs, equipments and services of trained mid-wife for the purpose of conducting normal deliveries in these institutions.

8. Provision of Administrative Expenses: Upto $4 \%$ and $1 \%$ of the fund released could be utilized towards administrative expenses like monitoring, IEC and office expenses for implementation of JSY by the district and state authorities respectively.

9. Essential Strategy: While the scheme would create demand for institutional delivery, it would be necessary to have adequate number of $24 \times 7$ delivery services centre, doctors, mid-wives, drugs etc. at appropriate places. Mainly, this will entail

- Linking each habitation (village or a ward in an urban area) to a functional health centre-public or accredited private institution where $24 \times 7$ delivery service would be available,

- Associate an ASHA or a health link worker to each of these functional health centre,

- It should be ensured that ASHA keeps track of all expectant mothers and newborn. All expectant mother and newborn should avail ANC and immunization services, if not in health centres, atleast on the monthly health and nutrition day, to be organised in the Anganwadi or sub-centre:

- Each pregnant women is registered and a micro-birth plan is prepared (please see Annexure-1)

- Each pregnant woman is tracked for ANC,

- For each of the expectant mother, a place of delivery is pre-determined at the time of registration and the expectant mother is informed,

- A referral centre is identified and expectant mother is informed,

- ASHA and ANM to ensure that adequate fund is available for disbursement to expectant mother,

- ASHA takes adequate steps to organize transport for taking the women to the pre-determined health institution for delivery,

- ASHA assures availability of cash for disbursement at the health centre and she escorts pregnant women to the pre-determined health centre. 
10. Possible IEC strategy:

- To associate NGO and Self Help Groups for popularizing the scheme among women's group and also for monitoring of the implementation.

- To provide wide publicity to the scheme by:

Promoting JSY as a component of total package of services under RCH along with programmes like Pulse polio programme, Monthly Village Health Day, Health Melas etc,

- Printing and distributing JSY guidelines, pamphlets, notices in local languages at SC/PHCs/CHCs/ District Hospitals/DM's and Divisional Commissioner's office and even in at the accredited Pvt. Nursing Homes, in abundance,

- Supporting printing of state's stationery, specially for State's Health Secretary, DMs/SDMs/Block/ PHC/CHC/District Hospital, advocating on Institutional Delivery and cash benefits of JSY,

- Facilitate organizing workshops and meetings in villages/blocks—by women's group, local leaders (PRIs), Opinion Maker, at functional health institutions on promoting maternal health in general, Institutional Delivery and JSY,

Undertaking wall painting in all sub-centers, PHCs and CHCs, District \& State Hospitals and the accredited private institutions,

Supporting women self help Groups and NGOs for promoting the scheme,

Facilitating woman Panchayat member to take review of Janani Suraksha Yojana (JSY)

11. Establish a grievance redressal cell in each district, under the District Project Management Unit, mainly to facilitate meeting people's genuine grievances on-

- Eligibility for the scheme,

- Quantum of cash assistance,

- Delays in disbursement of the cash assistance,

An officer, supported by an assistant, if necessary, may be made responsible to supervise the grievance cell. However, proper information about the grievance cell, giving the officer's name, postal address and his telephone number should be displayed prominently at all health centers and institutions. If necessary, fund available under administrative expenses could be utilized for this purpose.

12. Display of names of JSY beneficiaries: The list of JSY beneficiaries along with the date of disbursement of cash to her should mandatorily be displayed on the display board at the sub-center, PHC/CHC/District Hospitals (from where beneficiaries have got the benefit), being updated regularly on month-to-month basis. Wherever necessary, display boards may be procured. 
13. Guidelines for urban areas: The state shall prepare detailed guidelines by stating a simple procedure of implementing the Janani Suraksha Yojana (JSY) in the urban areas through the Municipalities/local bodies (where an elected body exits) and quickly obtain approval of the state Government/SHS. The guidelines should bring out clearly, the chain of fund flow as well as disbursement of the benefits to the ultimate beneficiaries. The quantum of grants to be placed at the disposal of the Municipalities shall be in proportion to the BPL families in the Municipal area. The district annual plan will also include the plan of the municipalities in the districts wherever applicable. The Chief medical Officer of such an authority should be the implementing authority. It must be ensured that basic objectives and the scale of disbursements are not altered. A copy such plan along with necessary Government's order should be sent to the GOI.

14. Monitoring:

14.1 Monthly Meeting at Sub-centre Level: For assessing the effectiveness of the implementation of JSY, monthly meeting of all ASHAs/related health link workers working under an ANM should be held by the ANM, possibly on a fixed day (may be on the third Friday) of every month, at the subcenter or at any of Anganwadi Centres falling under the ANM's area of jurisdiction. If Friday is a holiday, meeting could be held on following working day.

14.2 Prepare Monthly Work Schedule: In the monthly meeting, the ANM, besides reviewing the current month's work vis-à-vis envisaged activities, should prepare a Monthly Work Schedule for each ASHA/village level health worker of following aspects of the coming month:

- Feed back on previous month's schedule-

(a) Number of pregnant women missing ANCs,

(b) No. of cases, ASHA/link worker did not accompany the pregnant women for Delivery,

(c) Out of the identified beneficiary, number of Home deliveries,

(d) No. of post natal visits missed by ASHA,

(e) Cases referred to Referral Unit (FRU) and review their current health status,

(f) No. of children missing immunization.

- Fixing Next Month's Work Schedule (NMWS): To include-

(i) Names of the identified pregnant women to be registered and to be taken to the health center/Anganwadi for ANC,

(ii) Names of the pregnant women to be taken to the health center for delivery (wherever applicable),

(iii) Names of the pregnant women with possible complications to be taken to the health center for check-up and/or delivery, 
(iv) Names of women to be visited (within 7 days) after their delivery,

(v) List of infants/newborn children for routine immunization,

(vi) To ensure availability of imprest cash,

(vii) Check whether referral transport has been organized.

Note 1: While no target needs to be fixed, but for the purpose of monitoring, some monthly goal of institutional delivery for the village may be kept.

Note 2: A format of monthly work schedule to be filled by the ANM/ASHA incorporating the physical and financial aspect may be printed.

15. Reporting: For the purpose of reviewing the progress of implementation and also for allocating fund to the state, under the RCH-flexi Pool, all States would provide

- Annual District-wise report as per Annexure IV, reaching MoHFW in the month of April of the following financial year

- Quarterly Report as per Annexure V, reaching MoHFW in the month following the end of the Quarter.

However, depending on the requirement of the Ministry, special reports may also be sought.

\section{Most Important:}

16. Any deviation from the above process will not be accepted by the Central Government and that such expenditure will not be treated as legitimate utilization of the fund given under JSY. It may be noted that all payments before or after seven days of delivery will be treated as illegitimate subject to audit objection. 
Annexure 1: Micro-Birth Plan for JSY Beneficiaries

\begin{tabular}{|c|c|c|c|}
\hline Step & Activity & To be undertaken by & Proposed Time Line \\
\hline 1 & $\begin{array}{l}\text { Identification and Registration of } \\
\text { beneficiary }\end{array}$ & $\begin{array}{l}\text { ANM/ASHA/AWW or any link } \\
\text { worker }\end{array}$ & $\begin{array}{l}\text { Atleast } 20-24 \text { weeks before } \\
\text { the expected date of delivery. }\end{array}$ \\
\hline 2 & $\begin{array}{l}\text { Filling up of Maternal and Child } \\
\text { card (In duplicate-one each for } \\
\text { mother and ASHA/Link worker) }\end{array}$ & $\begin{array}{l}\text { ANM/ASHA/AWW or an } \\
\text { equivalent link worker }\end{array}$ & Immediately on registration \\
\hline & $\begin{array}{l}\text { (This will form part of the JSY'S } \\
\text { Registration Card). }\end{array}$ & & \\
\hline \multirow[t]{7}{*}{3} & $4 \mathrm{I}-\mathrm{s}^{\prime}:$ & ANM/ASHA/AWW or an & \\
\hline & $\begin{array}{l}\text { Inform dates of } 3 \text { ANC \& TT } \\
\text { Injection (s) }\end{array}$ & equivalent link worker & \\
\hline & $\begin{array}{l}\text { Identify the health center for all } \\
\text { referral }\end{array}$ & & Immediately on registration \\
\hline & Identify the Place of Delivery & & \\
\hline & Inform expected date of delivery & $\begin{array}{l}\text { Provide the } 1 \text { st ANC } \\
\text { immediately on Registration }\end{array}$ & \\
\hline & & $\begin{array}{l}\text { ASHA to follow up the ANCs } \\
\text { at the Anganwadi Centres/Sub- } \\
\text { center (SC) and ensure that } \\
\text { the beneficiary attends the SC/ } \\
\text { Anganwadi centre/PHC for ANC } \\
\text { on the indicated dates }\end{array}$ & \\
\hline & & $\begin{array}{l}\text { Motivation: ANM should call } \\
\text { the beneficiary to the Anganwadil } \\
\text { SC to participate in the Monthly } \\
\text { meeting and explain enhanced } \\
\text { cash and Transport assistance } \\
\text { benefits for Institutional delivery }\end{array}$ & \\
\hline \multirow[t]{2}{*}{4} & $\begin{array}{l}\text { Collecting BPL or necessary } \\
\text { proofs/certificates }\end{array}$ & & \\
\hline & $\begin{array}{l}\text { Wherever necessary from } \\
\text { Panchayat/local bodies/ } \\
\text { Municipalities }\end{array}$ & $\begin{array}{l}\text { ANM/ASHA/AWW or an link } \\
\text { worker }\end{array}$ & $\begin{array}{l}\text { Within } 2-4 \text { weeks from } \\
\text { Registration }\end{array}$ \\
\hline \multirow[t]{3}{*}{5} & $\begin{array}{l}\text { Submission of the completed JSY } \\
\text { card in the Health center for } \\
\text { verification by the authorized/ } \\
\text { Medical officer }\end{array}$ & $\mathrm{MO}, \mathrm{PHC}$ & $\begin{array}{l}\text { Atleast } 2-4 \text { weeks before the } \\
\text { expected date of delivery }\end{array}$ \\
\hline & $\begin{array}{l}\text { II. Take necessary steps toward } \\
\text { arranging transport or making } \\
\text { available cash to the beneficiary } \\
\text { to come to the Health Centre }\end{array}$ & ANM/ASHA/AWW/link worker & \\
\hline & $\begin{array}{l}\text { III. Ensure availability of fund to } \\
\text { ANM/Health worker/ASHA etc. }\end{array}$ & ANM/MO, PHC & \\
\hline 6. & $\begin{array}{l}\text { Payment of cash benefit/incentive } \\
\text { to the mother and ASHA }\end{array}$ & ANM/MO, PHC & At the institution \\
\hline
\end{tabular}


For complicated cases or those requiring cesarean section etc:
Ac-1 Pre-determine a Referral health center and intimate the pregnant women
Ac-2 Familiarize the woman with the referral centre, if necessary carry a letter of referral from $\mathrm{MO} \mathrm{PHC}$
Ac-3 Pre-organize the transport facility in consultation with family members/community leader
By ANM/ASHA/link worker
ANM/ASHA/link worker
ANM/ASHA/Community
Ac-4 Arrange for the medical experts if the same is not available in the referred heath center
MO, PHC

\section{Annexure 2: Criteria for Accreditation of 24 Hours Comprehensive Emergency Obstetric Care}

\section{Casualty services}

- A pregnant woman in labour or distress on entering the hospital at any time during the day or night is directly taken to the obstetric casualty and immediately examined by a professional with midwifery skills and decision taken within fifteen minutes

- If there are signs or bleeding, convulsions or shock, she should be immediately attended by the Obstetrician on duty and necessary treatment to be initiated

- Send the mother to the labour room, ward or operation theatre, depending on the signs and symptoms

- No pregnant woman in labour or distress should be turned away from the hospital for any reason at any time of the day or night

- Casualty should be located close to the labour room and theatre

- Casualty to receive advance intimation about the arrival of the mother and keep the specialist team ready with blood, if needed

- Casualty should have the following round the clock:

- An obstetrician

- $\quad$ Life saving drugs and IV fluids

- Facility for examining the patient (including pv)

- Emergency protocols

- Telephone connection in the casualty, labour room and blood bank

- Patient transport system within the institution 


\section{Emergency Obstetric Procedures}

- Procedures

- Vaccum extraction

- Forceps delivery

- $\quad$ LSCS

- Emergency Hysterectomy

- Manual removal of placenta

- Dilation and Curettage

- Laparotomy

- Blood transfusion

- Facilities

- Separate theatre for above obstetric procedures

- The Government shall provide at least 4 obstetricians, 4 paediatricians, 2 general surgeons and 2 anaesthetists to each CEmONC centre

Emergency Newborn Care

- Every delivery to be attended by a staff nurse trained in newborn resuscitation

- Paediatricians to be available in the institution round the clock for emergency interventions

- Emergency Protocol should be available

Laboratory Services

- 24 hours laboratory services including

- Blood grouping, typing and cross matching

- All routine examinations such as haemoglobin, blood glucose, urine sugar, albumin

\section{Post Natal Care}

All normally delivered mothers should be observed in the labour room for at least two hours after delivery.

Before transferring the mothers to the postnatal ward, pulse, BP, firmness of the uterus and amount of vaginal bleeding should be checked.

In the postnatal ward vital signs and height of the uterus should be monitored once in two hours for the first six hours and once in six hours till 24 hours. Twice a day monitoring until discharge should follow this.

Those mothers who had instrumental vaginal delivery should be observed in the labour ward for six hours after delivery before transferring the mother to the postnatal ward pulse, BP, firmness of the uterus, urine 
output and amount of vaginal bleeding should be checked. Postnatal care in the ward is similar to the care provided for normal vaginal delivery.

\section{Post Operative Care}

- Staff

- For the first two hours after surgery, staff nurse remains at the bedside to monitor patient continuously

- Hourly checkups of vital signs (temperature, pulse, BP, and urine output), for the next six hours

- Forth hourly check up of vital signs by staff nurse for next two days and thereafter twice daily till discharge

- Check up by doctor at least once during the first two hours and every sixth hourly for three days and then twice daily till discharge

Records and Registers

- Parturition Register

- Case Records

- Reporting Formats

- Referral register

Ambulance Services

- For referral

- Ambulance with driver and fuel available 24 hours

- Linkages with other ambulance providers

- Casualty to have telephone attender who will organise the transportation

Adherence to standard emergency treatment protocol

- Standard emergency treatment protocol should in the casualty, in labour ward and in theatre

- The obstetrician and staff nurse posted in the labour ward and theatre should be thorough with emergency protocol

Quality of provider-Patient interaction

- Patient treated with respect and dignity

- Privacy and confidentiality assured

- Informal payment from patients strictly banned

- Informed consent obtained from the family for major procedure

- Procedures clearly explained to family members

- A female attendant to be permitted in labour room while ensuring asepsis 


\section{Annexure 3: Janani Suraksha Yojana (JSY) Frequently Asked Questions and Answers}

Q. 1 Has the National Maternity Benefit Scheme (NMBS) been replaced by the Janani Suraksha Yojana (JSY) from FY 2005-06?

Ans. Yes. A new 100\% centrally sponsored scheme-Janani Suraksha Yojana (JSY) has been launched w.e.f 12.04.05. However, the cash benefits of the National Maternity Benefit Scheme (NMBS) have been incorporated in the Yojana.

Q. 2 Why Janani Suraksha Yojana?

Ans. The NMBS was not addressing all the concerns of safe motherhood in a focused manner. Need is felt for a comprehensive package for obstetric care services to save the lives of the mother and the newborn. The main objectives of JSY are to reduce maternal and neo-natal mortality by promoting institutional delivery for making available medical care during pregnancy, delivery and post delivery period.

Q. 3 Is there any change with regards to eligibility criterion for availing benefits of Janani Suraksha Yojana?

Ans. The scheme has expanded the eligibility criterion. As in October 2006, eligibility for cash assistance for institutional delivery is as follows:

LPS States All pregnant women delivering in Government health centers like Sub-centre, PHC/ CHC/FRU/general wards of District and state Hospitals or accredited private institutions

HPS States BPL pregnant women, aged 19 years and above

LPS \& HPS All SC and ST women delivering in a government health centre like Sub-centre, PHC/ $\mathrm{CHC/FRU/general} \mathrm{ward} \mathrm{of} \mathrm{District} \mathrm{and} \mathrm{state} \mathrm{Hospitals} \mathrm{or} \mathrm{accredited} \mathrm{private} \mathrm{institutions}$

Q. 4 What is basis of LPS and HPS states?

Ans. States with lower levels of institutional delivery rates have been classified as LPS states. These are-the states of Uttar Pradesh, Uttaranchal, Bihar, Jharkhand, Madhya Pradesh, Chhattisgarh, Assam and Jammu and Kashmir. The remaining states are named as HPS states.

Q. 5 Why there are the special dispensations for pregnant women from LPS states?

(i) Age certificate is not an instrument that is available easily. Many LPS states have yet to get the process of birth registration organised in rural areas. In view of this, for all BPL pregnant women belonging to LPS states, any kind of age certification would not be insisted upon for availing the benefits of JSY.

(ii) Removal of restrictions on the number of child births: Restricting the benefits upto 2 births would in fact encourage women of higher fertility in the LPS states to deliver at home in an unsafe condition. Such women are exposed to higher risks of mortality and morbidity too because of neglect on their part to access health care and facilities. Therefore, the restriction on the number of childbirths for accessing benefits of JSY has been removed. In other words, the benefits of the scheme are extended to all BPL pregnant women in LPS states irrespective of birth orders. 
(iii) Institutional delivery being the primary strategy for promoting safe motherhood, it is necessary that all women are encouraged to avail institutional care. With a view to encourage women from poor families to access public health institution for delivery, in LPS states, the benefits of JSY would be extended to all women (BPL and APL) availing institutional delivery care in Govt. health centres like SC, PHC, CHC, FRUs and general wards of the District and State Hospitals.

Q. 6 Is it mandatory to implement JSY?

Ans. Yes.

Q. 7 Is there any cash benefit for pregnant women from BPL families preferring to deliver at home?

Ans. In LPS and HPS States, BPL pregnant women, aged 19 years and above preferring to deliver at home is entitled to cash assistance of Rs. 500/- per delivery. Such cash assistance would be available only upto 2 live births and the disbursement would be done at the time of delivery. The rationale is that beneficiary would be able to use the cash assistance for her care during delivery or to meet incidental expenses of delivery.

Q. 8 If the focus of the scheme is to promote institutional delivery, why should there be a provision for home delivery?

Ans. It is true that we have to discourage home delivery. However, in view of the Hon'ble Supreme Court's direction, it is mandatory to provide for home delivery. In case of home delivery, cash benefits of JSY are as provided under NMBS. It would be the responsibility of the ANM, ASHA to counsel the pregnant woman to deliver in a health institution.

Q. 9 If the Government's policy is to control population, why would Government be relaxing two child restrictions under the Yojana?

Ans. It is true that couples in the reproductive age group, should have all the options to decide their family size and that the Government should endeavor to adhere to its stated population policy. JSY is a scheme for saving the lives of mothers from the causes related to delivery, which is also a stated policy of the Government. Women who are in the higher orders of birth, are more at risk of mortality, as they tend to neglect their delivery care and it is by bringing them to institution, and not by keeping them out of the domain of institutional delivery care that these high fertility women could be counseled for family planning.

Q. 10 When would the cash benefit under JSY be disbursed?

Ans. The cash benefit should be disbursed to the beneficiary preferably at the institution. If ASHA is unable to organize transport (wherever applicable) disbursement of transport assistance should be done in the health centre as soon pregnant women arrive and registers for delivery. It should be the responsibility of ANM, MO, PHC/ASHA to take all proactive actions to ensure timely disbursement. 
Q. 11 What is the rationale for disbursing the cash at the time of delivery?

Ans. It is desired that the cash benefit available under this scheme is used by the beneficiary for pregnancy related care especially at the time of delivery and also for post delivery care. If cash is given earlier, it is possible that it may be expended for other purposes.

Q. 12 If after having received the cash benefit, the child dies, would the benefit under JSY be extended for the next birth?

Ans. Yes. Proper record should be maintained.

Q. 13 If a still child is born in a health institution, can the benefit of JSY be disbursed to the mother?

Ans. Yes. Proper record should be maintained.

Q. 14 What is the scale of transport assistance out of ASHA package?

Ans. Generally, an amount of Rs. 250/- may be earmarked for this. It is, however, upto the State Government to determine the scale of transport assistance. It may be ensured that the incentive to ASHA which is part of ASHA package should not be less then 200/- per delivery facilitated by her, in addition to the transactional cost of around Rs. 150/- per delivery for escorting and staying with the mother in the health centre. It may be mentioned that ASHA would get cash benefit only if she accompanies the pregnant woman to the health centre.

Q. 15 Where would the transport assistance money be kept?

Ans. Keeping in view, the need to make available the cash required to transport women in the critical condition of delivery to a health centre, transport assistance amount should be kept with the ASHA with clear knowledge of the beneficiary. The mode of transport should be pre-decided by the ANM/ medical officers/family member. A proper protocol for arranging the transport should be put in place with assistance of the community, ASHA and the ANM.

Q. 16 Can the parameters of the JSY be modified by the states/UTs?

Ans. No. However, if any state or UT has any cogent reason for modifying, it is welcome, in consultation with the GOI. But kindly note that unilateral change by any state or UT is not advisable as it may lead to audit objections.

Q. 17 A poor woman needs treatment for C-Section or other obstetric complications. Is there any provision for such situations under JSY?

Ans. Yes. Generally FRUs/CHCs etc. would provide emergency obst. services free of cost. Where Government specialists are not available in the Govt's health institution, assistance up to Rs. 1,500/per case could be utilized by the health institution for hiring services of experts to carry out the surgery in a Government medical facility. Remember, this assistance is to the Govt. health institution and not to the beneficiary. 
Q. 18 Generally, in remote areas, even a private medical expert is not available. What to do then?

Ans. In such a situation, expert doctors working in the other Government health institutions may even be empanelled provided his/her services are spare. The cash assistance for C-section or any other obstetric complications, limited to Rs. 1,500 per case, can be utilized to pay honorarium or for meeting transport cost to bring the expert to health centre. It may however be remembered that a panel of such doctors need to be prepared beforehand by all such health institutions where such facility would be provided and the pregnant women are informed of this facility, at time of micro-birth planning.

\section{LINKAGE WITH ASHA}

Q. 19 What is the role of ASHA under JSY?

Ans. ASHA is to act as a facilitator and is an important component of the JSY strategy. Her main roles would be as follows:

- Identify pregnant woman as a beneficiary of the scheme and report or facilitate registration for ANC,

- Assist the pregnant woman to obtain necessary certifications wherever necessary,

- Provide and/or help the women in receiving at least three ANC including TT injections, IFA tablets,

- Identify a functional Government health centre or an accredited private health institution for referral and delivery,

- Counsel for institutional delivery,

- Escort the beneficiary women to the pre-determined health canter and stay with her till the woman is discharged,

- Arrange to immunize the newborn till the age of 10 weeks,

- Inform ANM/MO about the birth or death of the child or mother,

- Post natal visit within 7 days of delivery and track mother's health,

- Counsel for initiation of breastfeeding to the newborn within one-hour of delivery and its continuance till 3-6 months and promote family planning.

The compensation package for ASHA is available to her if she escorts/stays with the pregnant women in the health centres.

Q. 20 What is a micro-birth plan?

Ans. The scheme is not of distributing cash benefit, but of providing quality maternity services to the pregnant women too. Microbirth plan is a tool for efficient coordination of all the activities. It mainly entails-

- Essential activities,

- Who would perform the activities, and

- The desired timeline. 
Q. 21 Is it mandatory?

Ans. Yes. It is mandatory to draw a Micro-birth plan for each JSY beneficiary besides filling up a Maternal and Child Health Card (MCH Card).

Q. 22 Who would draw the micro-birth plan?

Ans. The micro-birth plan would be drawn by the ANM. ASHA or any other link work would assist and it is essential that they know the component of the birth plan.

Q. 23 What are the essential components of a micro-birth plan?

Ans. Inform the mother and the family about 4 Is, namely-

- Inform dates of 3 ANC \& TT Injection (s) and ensure these are provided,

- Identify the health centre for all referral,

- Identify the Place of Delivery,

- Inform expected date of delivery.

In addition,

- Collecting BPL or necessary proofs/certificates

- Timely submission of the completed JSY card in the Health centre for verification by the authorized/ Medical officer,

- Arranging transport for the beneficiary to go to the Health Centre for delivery or complications, well in advance,

- Ensuring availability of fund with the ANM/link Health worker/ASHA etc.

Q. 24 How would ASHA's work be adjudged under this scheme?

Ans. Work of the ASHA should be assessed based on the number of pregnant women she has been able to motivate to deliver in a health institution.

Q. 25 Where ASHA has not been recruited; can the ASHA package be disbursed to Anganwadi Worker or to any link worker/Trained Birth Attendant (TBA)?

Ans. If the Anganwadi worker or the TBA performs all the activities of the ASHA, the ASHA package can be disbursed to them, only till the time ASHA is available in the village.

Q. 26 When a beneficiary does not utilize the services of ASHA even if she is in place, can ASHA package be disbursed?

Ans. No. 
Q. 27 Will ASHA receive any compensation package if she does not escort the pregnant women to the health centre during delivery?

Ans. If ASHA does not do the antenatal protocol nor she escorts the pregnant women, she will not receive the compensation package.

However, if ASHA has done the ANC protocol (Please ensure from AWW/ANM through a due process set out by the medical officer, PHC) and arranges an escort after due recording of the reasons for not being able to escort the pregnant women (in a register maintained by ANM for micro-planning of the delivery of the registered beneficiaries), the package available to ASHA may be disbursed to her. The officials concerned should exercise due caution and carry out proper checks before disbursement of such cash benefits.

In such a situation when ASHA or any other health worker-AWW/ANM does not escort the pregnant women to a health centre, the eligible pregnant women would get additional benefit of the admissible cash benefit earmarked for transport assistance out of the ASHA's package.

Q. 28 Is the reporting of the implementation status giving details of fund utilized and number of beneficiaries benefited under the JSY to the Ministry of Health \& Family Welfare, mandatory?

Ans. Six-monthly district wise report need to be sent mandatorily to the central government. This will form the basis of release of further grants.

Q. 29 Is there a role for the Gram Panchayat under the JSY?

Ans. Where Panchayati Raj Institutions (PRIs) exist and an elected body is in place, the State Governments/District society may keep the money in the joint accounts of the ANM and the Gram Pradhan. The Panchayat and the local bodies need to be effectively involved in BPL certification process in a manner that genuine poor pregnant women are able to benefit from the scheme.

Q. 30 Is it mandatory to keep an imprest with ANM?

Ans. Yes. A recoupable imprest of Rs. 5,000/- should be kept with ANM. The purpose is to make quick disbursement to the beneficiary. Out of this, the ANM should keep atleast Rs. 1,500/- (recoupable) with the ASHA/Anganwadi Worker so that when the pregnant women need to be taken to the health institution for delivery, ASHA is able to organize transport quickly. This would quicken the process of disbursement that is key to the success of JSY.

\section{FINANCIAL MATTERS}

Q. 31 Is there a separate budget/allocation for JSY?

Ans. Unlike under NMBS, grants for JSY will be released to the State Health Society (SHS) as part of $\mathrm{RCH}$ flexi pool, based on the recommendation of the NBCC and the State's PIP. It would be upon the SHS to allocate and disburse the JSY fund to the District Health Society (DHS). 
Q. 32 Is there any component under the JSY grant to meet certain essential expenditures, as a part of the administrative expenses? If yes, what are the activities permissible under the administrative expenses?

Ans. $\quad$ Yes, Upto $4 \%$ and $1 \%$ of the fund released could be utilized towards administrative expenses like monitoring, IEC and office expenses for implementation of JSY by the district and state authorities respectively.

\section{BPL CERTIFICATION}

Q. 33 If poor pregnant women do not have BPL Card but otherwise considered very poor and needy by the community, how to certify and disburse cash benefit under JSY?

Ans. The Panchayat and the local bodies need to be effectively involved in the certification of poor and needy expectant mother, in a manner that genuine poor pregnant women are able to benefit from the scheme. However, if the BPL certification is not available through a legally constituted process, the beneficiary could still access the benefit on certification by Gram Panchayat/pradhan provided the delivery takes place in a Government institution. The benefit available under JSY will be admissible in a private hospital only against a regular BPL card whose number etc. has to be quoted in the birth certificate to be issued by the private institution.

Q. 34 Will there be any requirement of BPL card in LPS states?

Ans. No, provided women access government or accredited health institution for delivery. However, for getting cash component for home delivery, BPL card would be essential.

Q. 35 What about SC and SC women?

Ans. Such women would also not require a BPL certification if they access government or accredited health institution for delivery.

Q. 36 Can cash benefit of the mother be handed over to the institution, in lieu of the services provided?

Ans. No. Cash benefit to mother has to be given to the mother. It is upto the mother to decide, asto how it is to be utilized. Any deviation in this regard would be construed as violation and may lead to audit objections.

Q. 37 When would the ASHA package be disbursed?

Ans. ASHA package is to disbursed in two installment. Transactional cost to be paid to ASHA in lieu of her stay with the pregnant woman in the health centre for delivery should be paid at the hospital/ heath institution itself. And, cash incentive to ASHA, being not less than Rs. 200/- per delivery in lieu of facilitating institutional delivery should be paid after her post natal visit to the newly delivered mother and the newborn has been immunized for BCG. 


\section{References}

Centre for Operations Research and Training (CORT). 2007a. Assessment of Janani Suraksha Yojana in Assam. Vadodara: CORT.

Centre for Operations Research and Training (CORT). 2007b. Assessment of Janani Suraksha Yojana in Himachal Pradesh. Vadodara: CORT.

Centre for Operations Research and Training (CORT). 2007c. Assessment of ASHA and Janani Suraksha Yojana in Madhya Pradesh. Vadodara: CORT; New Delhi: UNICEF.

Centre for Operations Research and Training (CORT). 2007d. Assessment of ASHA and Janani Suraksha Yojana in Orissa. Vadodara: CORT; New Delhi: UNICEF.

Centre for Operations Research and Training (CORT). 2007e. Assessment of ASHA and Janani Suraksha Yojana in Rajasthan. Vadodara: CORT; New Delhi: UNICEF.

Centre for Operations Research and Training (CORT). 2007f. Assessment of Janani Suraksha Yojana in West Bengal. Vadodara: CORT.

Centre for Operations Research and Training (CORT). 2008a. Assessment of Janani Avam Bal Suraksha Yojana in Bihar. Vadodara: CORT; New Delhi: UNICEF.

Centre for Operations Research and Training (CORT). 2008b. Assessment of Janani Suraksha Yojana in Uttar Pradesh. Vadodara: CORT; New Delhi: UNICEF.

International Institute for Population Sciences (IIPS) and Macro International. 2008. National Family Health Survey (NFHS-3), India, 2005-06: Rajasthan. Mumbai: IIPS.

International Institute for Population Sciences (IIPS). 2010. District Level Household and Facility Survey (DLHS-3), 2007-08: India. Mumbai: IIPS.

Ministry of Health and Family Welfare (MOHFW). 2006. Janani Suraksha Yojana: Features and Frequently Asked Questions and Answers. New Delhi: MOFHW, Government of India. Accessed on 21 September 2010 athttp://www.mohfw.nic.in/WriteReadData/1892s/file28-99526408.pdf.

Ministry of Health and Family Welfare (MOHFW). 2011a. Update on the ASHA Programme, New Delhi: MOHFW, Government of India.

Ministry of Health and Family Welfare (MOHFW). 2011b. ASHA: Which Way Forward? Evaluation of ASHA Programme, New Delhi: MOHFW, Government of India.

Ministry of Health and Family Welfare (MOHFW). 2011c. Fourth Common Review Mission Report 2010, New Delhi: Government of India.

Ministry of Health and Family Welfare (MOHFW). n.d. ASHA-Accredited Social Health Activist. New Delhi: MOHFW, Government of India. Accessed on 18 January, 2011 at http://www.mohfw.nic.in/NRHM/asha. htm\#abt. 
Implementing the Janani Suraksha Yojana: Perspectives and experiences of Accredited Social Health Activists in Rajasthan

Office of Registrar General, India. 2011. Special bulletin on maternal mortality in India 2007-09, Sample Registration System. New Delhi: Office of the Registrar General, India.

Office of the Registrar General and Census Commissioner, India. 2011. Provisional Population Totals, Paper 1 of 2011: Census of India 2011, Series I-India. New Delhi: Office of the Registrar General, India.

Planning Commission. 2011. Mid-Term Appraisal Eleventh Five Year Plan 2007-2012. New Delhi: Oxford University Press.

Santhya, K. G., S. J. Jejeebhoy, R. Acharya and A. J. Francis Zavier. 2011. Effects of the Janani Suraksha Yojana on maternal and newborn care practices: Women's experiences in Rajasthan. New Delhi: Population Council.

United Nations Children Fund (UNICEF). 2010. Coverage Evaluation Survey 2009. UNICEF: New Delhi.

United Nations Population Fund. 2009. Concurrent Assessment of Janani Suraksha Yojana (JSY) Scheme in Selected States of India, 2008. Accessed on 22 September, 2010 at http://www.mohfw.nic.in/NRHM/Documents/ JSY_Study_UNFPA.pdf. 


\section{Members of the study team}

$\begin{array}{ll}\text { Investigators } & \\ \text { Babita Bansod } & \text { Neha Panday } \\ \text { Geeta Gupta } & \text { Prem Kanwar Rathore } \\ \text { Priya Gupta } & \text { Premlata Rathore } \\ \text { Ravi Jain } & \text { B.Srihari } \\ \text { Binit Jha } & \text { Rituraj Solanki } \\ \text { Dlilshad Khan } & \text { Mukesh Vijay } \\ \text { Najma Khan } & \text { Pushplata Yadav } \\ \text { Nikhat Khan } & \text { Radha Yadav } \\ \text { Manisha Kaushal } & \text { Rukmani Yadav } \\ \text { Irshad Mohammad } & \text { Sheela Yadav } \\ \text { Editor } & \\ \text { Jyoti Moodbidri } & \\ \text { Komal Saxena } & \end{array}$

Administration

M A Jose 


\section{Authors}

K G Santhya, Associate II, Population Council, New Delhi

Shireen J Jejeebhoy, Senior Associate, Population Council, New Delhi

A. J. Francis Zavier, Programme Officer, Population Council, New Delhi 



\section{(P Population Council}

Zone 5-A, Ground Floor India Habitat Centre

Lodi Road

New Delhi 110 003, India 